\title{
VARIABILIDADE ESPAÇO-TEMPORAL E INTERANUAL DA CHUVA NO ESTADO DO RIO DE JANEIRO
}

\author{
SOBRAL, Bruno Serafini- brunossobral@gmail.com \\ Universidade Federal Fluminense/ UFF
}

OLVEIRA-JÚNIOR, José Francisco - jose.junior@icat.ufal.br Universidade Federal do Alagoas / UFAL

\author{
GOIS, Givanildo - givanildogois@gmail.com \\ Universidade Federal Fluminense/ UFF
}

TERASSI, Paulo Miguel de Bodas - pmbterassi@usp.br Universidade de São Paulo / USP

\author{
MUNIZ-JÚNIOR, João Gualberto Rodrigues - gualberto268@gmail.com \\ Universidade Federal Fluminense/ UFF
}

\begin{abstract}
RESUMO: O objetivo deste artigo é caracterizar a variabilidade espaço-temporal e interanual da chuva no Estado do Rio de Janeiro (ERJ) entre 1979 e 2009. Para isso foram utilizados dados de chuva de 99 estações pluviométricas, meteorológicas convencionais e automáticas distribuídas nas oito regiões de Governo do ERJ. As regiões de Governo com os maiores percentuais médios de falhas registradas foram Metropolitana, Costa Verde, Baixadas Litorâneas, Centro Sul, Médio Paraíba, Norte, Serrana e Noroeste. As falhas identificadas foram preenchidas com os dados do produto 3B43 do satélite TRMM e com as normais climatológicas do Instituto Nacional de Meteorologia. A chuva média anual do período de estudo obtida para o estado foi de $1544 \mathrm{~mm}$. As regiões Baixadas Litorâneas $(2144 \mathrm{~mm})$, Costa Verde (1912 mm), Médio Paraíba (1602 mm), Metropolitana $(1571 \mathrm{~mm})$ e Serrana $(1547 \mathrm{~mm})$ registraram média maior que a média estadual do período, enquanto as regiões Centro Sul $(1307 \mathrm{~mm})$, Noroeste $(1235 \mathrm{~mm})$ e Norte $(1033 \mathrm{~mm})$ ficaram abaixo da média. Todas as regiões registraram meses menos chuvosos em junho, julho e agosto. Já os meses com maiores totais de chuva foram registrados entre novembro e março, dependendo da região. A alta influência do relevo (altitude) no regime de chuva em todo o ERJ ficou caracterizada, principalmente nas Serras dos Órgãos e da Mantiqueira. As estações localizadas na vertente voltada para oceano Atlântico (barlavento) registraram as maiores médias anuais de chuva do estado, ao passo que regiões de relevo menos acidentado (Norte e Noroeste), ou com vertente voltada para continente (sotavento) das principais barreiras orográficas, registraram chuva média anual com valores inferiores à média estadual
\end{abstract}

PALAVRAS-CHAVES: Precipitação, Rio de Janeiro, fatores fisiográficos, variabilidade climática.

\section{SPATIAL TEMPORAL AND INTERANUAL RAINFALL VARIABILITY IN THE STATE OF RIO DE JANEIRO}

ABSTRACT: This article aims to characterize the temporal and interannual variability of rainfall in the State of Rio de Janeiro (ERJ) between 1979 and 2009. For this, rainfall data of 99 conventional and automatic rainfall meteorological stations distributed in the regions were used. Data faults were filled with data from product 3B43 of the TRMM satellite and climatological normal values provided by INMET. The state average annual rainfall for the period was $1544 \mathrm{~mm}$. Baixadas Litorâneas (2144 mm), Costa Verde (1912 $\mathrm{mm})$, Médio Paraíba $(1602 \mathrm{~mm})$, Metropolitana $(1571 \mathrm{~mm})$ and Serrana $(1547 \mathrm{~mm})$ recorded a higher average than the state average for the period, while regions Centro Sul $(1307 \mathrm{~mm})$, Noroeste $(1235 \mathrm{~mm})$ and Norte $(1033 \mathrm{~mm})$ were below average. All regions 
registered less rainy months in June, July and August. The months with the highest rainfall totals were recorded between November and March, depending on the region. The great influence of the terrain (altitude) in the rainfall regime throughout the ERJ was characterized, mainly in ridges such as Serra dos Órgãos and Serra da Mantiqueira. The stations located on the slope facing the Atlantic Ocean (windward) recorded the highest annual averages of rainfall in the state, while less rugged terrain regions (Norte and Noroeste), or slopes facing mainland (leeward) of the main orographic barriers, recorded annual average rainfall with values lower than the state average.

KEYWORDS: Precipitation, Rio de Janeiro, physiographic factors, climate variability.

\section{INTRODUÇÃO}

Atualmente, existe uma preocupação com os possíveis impactos devido ao aumento dos eventos climáticos extremos, tais como secas, enchentes, ondas de calor e de frio, furacões e tempestades, que têm afetado o planeta e vem causando prejuízos econômicos e sociais irreparáveis na sociedade (MARENGO, 2006, 2012; VICENTE-SERRANO et al., 2010; WADA, 2015; WANDERS,2015). Os estudos de Marcelino et al. (2006) e Wanders e Wada (2015) chamam atenção para a relação do crescimento populacional e das mudanças climáticas no mundo, evidenciando a necessidade de intensificar esforços nos estudos do clima como forma de minimizar seus efeitos adversos nas futuras gerações.

O Brasil é um dos países que sofrem constantemente com extremos climáticos, com destaque para a ocorrência de enchentes e deslizamentos de terra em centros urbanos, seguido da seca em diversas regiões do país. Desta forma, cabe ressaltar a relevância de estudos observacionais que visem à caracterização do regime de chuvas como forma de aperfeiçoar o entendimento a respeito da variabilidade pluviométrica nas diversas regiões do país.

O ERJ está inserido na região Sudeste do Brasil, que segundo Sant'Anna Neto (2005), configura-se como uma das mais diversificadas regiões brasileiras, em termos climáticos. A ocorrência de fortes chuvas, principalmente durante o verão austral, causa grande impacto nas atividades socioeconômicas dos estados inseridos nesta região (LIMA et al., 2010b). De acordo com Altamirano (2010), por situar-se nos subtrópicos, a região Sudeste apresenta uma faixa de transição entre duas regiões de diferentes comportamentos climáticos: clima tropical quente de uma região semi-árida ao norte (Nordeste do Brasil), clima tropical úmido/semiúdo com concentração de chuvas no verão no setor central (Brasil Central), e ao sul um clima mesotérmico do tipo temperado (Sul do Brasil).

A região Sudeste do Brasil possui uma característica climática diversificada, devido a sua topografia, sua posição geográfica e, principalmente, os aspectos dinâmicos da atmosfera, que incluem os sistemas meteorológicos de local, mesoescala e sinótico (REBOITA et al., 2010), que atuam direta ou indiretamente no regime de chuva, como a Zona de Convergência do Atlântico Sul (ZCAS) e as Frentes Frias (FF), principais responsáveis pela chuva, além do Anticiclone Subtropical do Atlântico Sul (ASAS) e o Vórtice Ciclônico de Altos Nivéis (VCAN) que, dependendo das suas posições, ocasionam grandes períodos de estiagens (KELLER FILHO et al., 2005; MINUZZI et al., 2007a). 
É comum no ERJ, em especial nos grandes centro urbanos durante o verão, a ocorrência de inundações, que são fenômenos naturais de grande impacto e ocorrem quando a intensidade das chuvas é alta e a vazão ultrapassa a capacidade de escoamento dos córregos e rios. Visto que entre 2010 e 2011, de acordo com Dourado et al. (2012), mais de mil pessoas morreram em desastres naturais causados por chuvas intensas no ERJ, nos municípios de Angra dos Reis (52 mortos em Janeiro de 2010), Niterói (166 mortos em Abril de 2010) e na Região Serrana do estado (947 mortos), cabe ressaltar os estudos já realizados por Machado et al. (2010); André et al. (2008), Brito et al. (2016) e Gois et al. (2017) como forma de aperfeiçoar o entendimento a respeito da variabilidade pluviométrica no estado.

A chuva no ERJ sofre considerável influência da topografia, com máximos nas áreas de elevada altitude e mínimos sobre as regiões de baixada e costeira (SILVA; DERECZYNSKI, 2014; SOBRAL, 2017). De acordo com Silva e Dereczynski (2014), os maiores índices pluviométricos médios anuais encontram-se na divisa da região Metropolitana e das Baixadas Litorâneas com a região Serrana, onde a pluviosidade média anual varia entre 2.500 e 2.800 mm. Apesar de alguns trabalhos como Blain e Kayano (2011), Minuzzi e Sediyama (2010), Altamirano (2010), Minuzzi et al., (2007a), Minuzzi et al., (2007b), Sant'Anna Neto (2005) e Davis e Naghettini (2000) abordarem a recorrência de chuva e a influência de outros fenômenos climáticos sobre o clima de áreas inseridas na região Sudeste, até o presente momento existe uma carência de estudos observacionais que busquem caracterizar a variabilidade espacial, temporal e interanual das chuvas no ERJ. Portanto, o objetivo deste artigo é caracterizar a variabilidade espaço-temporal e interanual da chuva no Estado do Rio de Janeiro entre 1979 e 2009.

\section{MATERIAL E MÉTODOS}

Foi utilizada série temporal mensal, com 31 anos consecutivos (19792009), de dados de chuva de 99 estações pluviométricas, meteorológicas convencionais e automáticas, distribuídas nas oito regiões de Governo do ERJ (Figura 1). A divisão regional dos dados de chuva foi adotada neste estudo as regiões administrativas de Governo, visto que são as principais unidades de planejamento de políticas públicas do Estado. Igualmente, a divisão regional acompanha, em sua maioria, os principais maciços do ERJ. As regiões administrativas tiveram como base a atual divisão político-administrativa do ERJ, disponibilizada por CEPERJ (2016). 


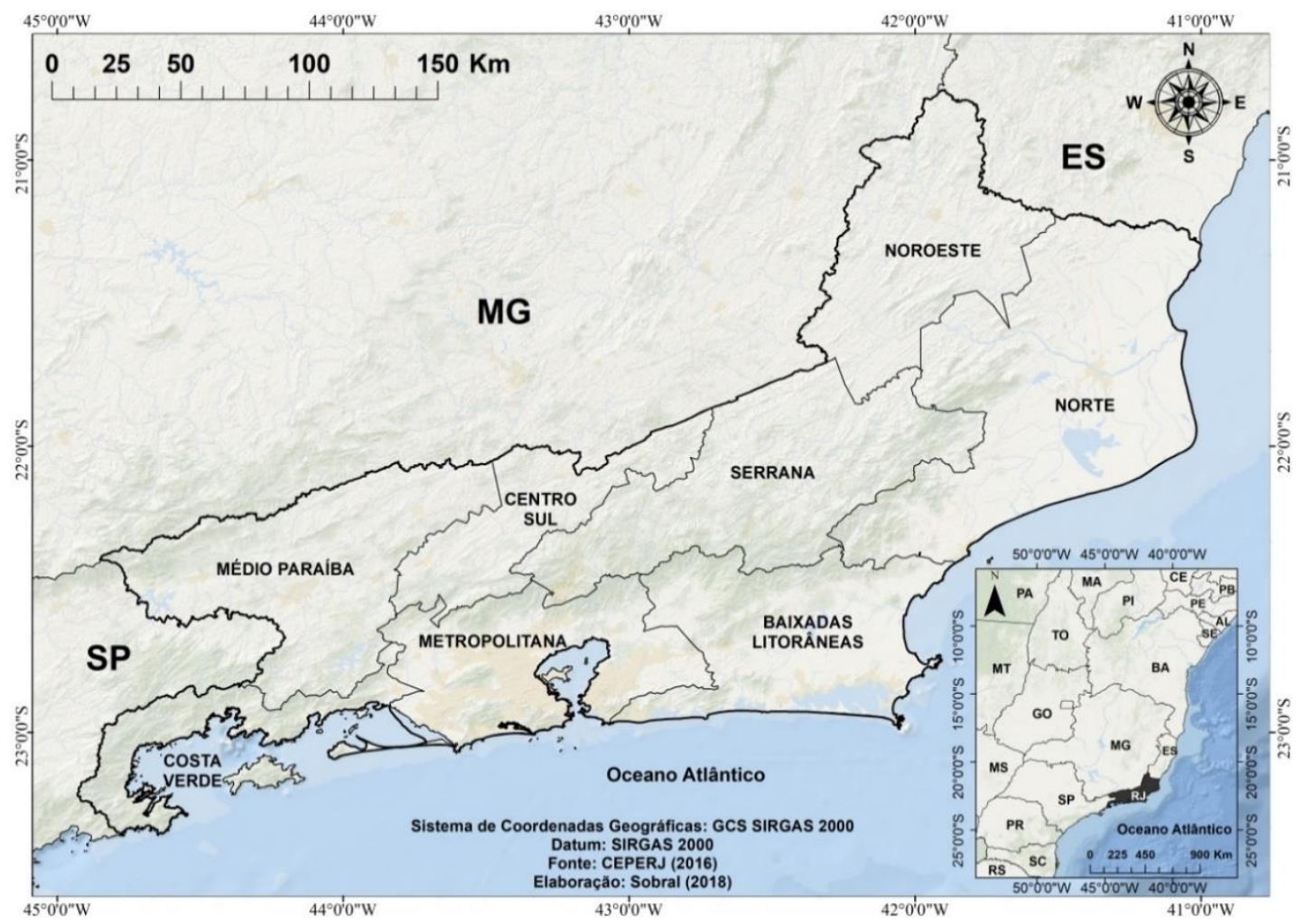

Figura 1 - Localização das regiões administrativas do estado do Rio de Janeiro.

Quanto ao número de estações utilizadas neste estudo, as regiões Serrana e Médio Paraíba foram caracterizadas a partir de dados pluviométricos de 27 estações cada. A região Metropolitana contou com 14 estações para caracterização pluviométrica, enquanto as regiões Norte e Baixadas Litorâneas foram caracterizadas utilizando-se dados de 8 estações. As regiões Noroeste e Centro Sul tiveram o regime de chuva analisado a partir de dados fornecidos por 6 estações, enquanto a região Costa Verde foi a que teve a menor quantidade de estações, apenas 3.

Os dados pluviométricos utilizados no estudo foram oriundos de diversas agências, tais como a ANA (Agência Nacional de Águas), CPRM (Companhia de Pesquisa de Recursos Minerais), INMET, SERLA (Fundação Superintendência Estadual de Rios e Lagoas) e LIGHT (Light Serviços de Eletricidade S/A). A Tabela 1 apresenta as 99 estações utilizadas para formar a série temporal pluviométrica, seguido da Figura 2 que ilustra a localização das estações dentro do ERJ.

Tabela 1 - Estações utilizadas no estudo para o período de 1979 a 2009 com as respectivas coordenadas geográficas, chuva média anual $(\mathrm{mm})$ e as falhas $(\%)$.

\begin{tabular}{|c|c|c|c|c|c|c|c|}
\hline ID & $\begin{array}{c}\text { Regiões de } \\
\text { Governo }\end{array}$ & $\begin{array}{c}\text { Estações } \\
\text { Pluviométricas }\end{array}$ & $\begin{array}{c}\text { Lat. } \\
\mathbf{(}^{\circ} \mathbf{)}\end{array}$ & $\begin{array}{c}\text { Long. } \\
\mathbf{(}{ }^{\circ} \mathbf{)}\end{array}$ & $\begin{array}{c}\text { Altitude } \\
\mathbf{( m )}\end{array}$ & $\begin{array}{c}\text { Chuva } \\
\text { Média } \\
\text { Anual } \\
\mathbf{( m m}\end{array}$ & $\begin{array}{c}\text { Falhas } \\
\mathbf{( \% )}\end{array}$ \\
\hline 1 & Norte & São Fidelis & $-21,65$ & $-41,75$ & 10 & 1056,3 & 10,66 \\
\hline 2 & Norte & $\begin{array}{c}\text { Campos dos } \\
\text { Goytacazes }\end{array}$ & $-21,75$ & $-41,33$ & 25 & 1083,11 & 4,44 \\
\hline
\end{tabular}




\begin{tabular}{|c|c|c|c|c|c|c|c|}
\hline 3 & Norte & Cardoso Moreira & $-21,49$ & $-41,61$ & 20 & 993,17 & 0,2 \\
\hline 4 & Norte & Dois Rios & $-21,64$ & $-41,86$ & 50 & 1139,18 & 0,2 \\
\hline 5 & Norte & Farol São Tomé & $-22,04$ & $-41,06$ & 2 & 319.622 & 0,2 \\
\hline 6 & Norte & Faz. Oratório & $-22,26$ & $-41,98$ & 50 & 1560,16 & 1,09 \\
\hline 7 & Norte & Macabuzinho & $-22,08$ & $-41,71$ & 19 & 1193,98 & 0,3 \\
\hline 8 & Norte & Usina Quissamã & $-22,11$ & $-41,47$ & 15 & 913,5 & 1,38 \\
\hline 9 & Noroeste & Itaperuna & $-21,21$ & $-41,91$ & 110 & 1136 & 4,34 \\
\hline 10 & Noroeste & Porciúncula & $-20,96$ & $-42,04$ & 188 & 1384,5 & 0,2 \\
\hline 11 & Noroeste & Varre-sai & $-20,93$ & $-41,85$ & 650 & 1479,69 & 0,99 \\
\hline 12 & Noroeste & $\begin{array}{l}\text { Sto. Antônio de } \\
\text { Pádua }\end{array}$ & $-21,54$ & $-42,18$ & 70 & 1169,46 & 0,39 \\
\hline 13 & Noroeste & Três Irmãos & $-21,63$ & $-41,99$ & 42 & 1125,88 & 0,1 \\
\hline 14 & Noroeste & Ponto de Pergunta & $-21,76$ & $-42,08$ & 61 & 1114,04 & 0 \\
\hline 15 & Serrana & Leitão da Cunha & $-22,04$ & $-42,04$ & 425 & 1791,81 & 1,18 \\
\hline 16 & Serrana & Maria Mendonça & $-22,19$ & $-42,16$ & 800 & 1962,95 & 0,99 \\
\hline 17 & Serrana & Sta. Maria Madalena & $-21,95$ & $-42,02$ & 620 & 1497,27 & 12,73 \\
\hline 18 & Serrana & Sossego do Imbé & $-21,90$ & $-41,80$ & 711 & 1509,07 & 0 \\
\hline 19 & Serrana & Visconde de Imbé & $-22,07$ & $-42,16$ & 334 & 1241,67 & 0 \\
\hline 20 & Serrana & Cordeiro & $-22,03$ & $-42,38$ & 485 & 1449,07 & 0 \\
\hline 21 & Serrana & Aldeia & $-21,95$ & $-42,36$ & 376 & 1284,04 & 0 \\
\hline 22 & Serrana & Carmo & $-21,93$ & $-42,62$ & 341 & 1524,41 & 11,15 \\
\hline 23 & Serrana & Paquequer & $-21,88$ & $-42,64$ & 150 & 869,59 & 0 \\
\hline 24 & Serrana & Bom Jardim & $-22,16$ & $-42,42$ & 530 & 1372,95 & 0 \\
\hline 25 & Serrana & $\begin{array}{c}\text { Cascatinha do } \\
\text { Conego }\end{array}$ & $-22,35$ & $-42,57$ & 1980 & 1587,08 & 0,59 \\
\hline 26 & Serrana & Faz. Mendes & $-22,29$ & $-42,66$ & 1010 & 1569,62 & 0,69 \\
\hline 27 & Serrana & Faz. São João & $-22,39$ & $-42,50$ & 1010 & 2130,37 & 0,1 \\
\hline 28 & Serrana & Galdinópolis & $-22,36$ & $-42,38$ & 740 & 1977,84 & 0 \\
\hline 29 & Serrana & Nova Friburgo & $-22,28$ & $-42,53$ & 857 & 1585,62 & 13,82 \\
\hline 30 & Serrana & Piller & $-22,40$ & $-42,34$ & 670 & 2356,45 & 0 \\
\hline 31 & Serrana & Sumidouro & $-22,05$ & $-42,68$ & 346 & 1385,33 & 0,2 \\
\hline 32 & Serrana & Vargem Alta & $-22,30$ & $-42,40$ & 1100 & 1450,75 & 0 \\
\hline 33 & Serrana & Barra Alegre & $-22,24$ & $-42,29$ & 650 & 1358,89 & 0 \\
\hline 34 & Serrana & Vargem Grande & $-22,28$ & $-42,50$ & 680 & 1548,21 & 0,2 \\
\hline 35 & Serrana & Bonsucesso & $-22,27$ & $-42,79$ & 870 & 1343,98 & 0,39 \\
\hline 36 & Serrana & Faz. Sobradinho & $-22,20$ & $-42,90$ & 650 & 1387,51 & 0,1 \\
\hline 37 & Serrana & Itamarati & $-22,49$ & $-43,15$ & 1025 & 1488,46 & 0 \\
\hline 38 & Serrana & Parada Moreli & $-22,20$ & $-43,03$ & 600 & 1288,67 & 0,3 \\
\hline 39 & Serrana & Pedro do Rio & $-22,33$ & $-43,14$ & 645 & 1305,01 & 0,1 \\
\hline 40 & Serrana & Petrópolis & $-22,51$ & $-43,17$ & 890 & 1967,79 & 0 \\
\hline 41 & Serrana & Rio da Cidade & $-22,44$ & $-43,17$ & 704 & 1521,13 & 0,2 \\
\hline
\end{tabular}




\begin{tabular}{|c|c|c|c|c|c|c|c|}
\hline 42 & Centro Sul & Usina Velha & $-22,02$ & $-43,30$ & 309 & 1418,73 & 24,28 \\
\hline 43 & Centro Sul & Areal - Granja Gabi & $-22,24$ & $-43,10$ & 450 & 1514,14 & 0,39 \\
\hline 44 & Centro Sul & Fagundes & $-22,30$ & $-43,18$ & 460 & 1149,47 & 1,18 \\
\hline 45 & Centro Sul & Moura Brasil & $-22,13$ & $-43,15$ & 270 & 1165,95 & 0 \\
\hline 46 & Centro Sul & Paraíba do Sul & $-22,16$ & $-43,29$ & 300 & 1105,69 & 0,1 \\
\hline 47 & Centro Sul & Três Rios Subestação & $-22,11$ & $-43,21$ & 300 & 1489,25 & 12,04 \\
\hline 48 & Costa Verde & Angra dos Reis & $-23,00$ & $-44,32$ & 2 & 1896,92 & 21,13 \\
\hline 49 & Costa Verde & Parati & $-23,22$ & $-44,76$ & 2 & 1492,33 & 0,59 \\
\hline 50 & Costa Verde & São Roque & $-23,07$ & $-44,70$ & 0 & 2346,11 & 1,18 \\
\hline 51 & $\begin{array}{c}\text { Baixadas } \\
\text { Litorâneas }\end{array}$ & Cabo Frio & $-22,88$ & $-42,03$ & 7 & 1506,5 & 27,54 \\
\hline 52 & $\begin{array}{l}\text { Baixadas } \\
\text { Litorâneas }\end{array}$ & Faz. do Carmo & $-22,44$ & $-42,77$ & 40 & 2108,45 & 0,3 \\
\hline 53 & $\begin{array}{l}\text { Baixadas } \\
\text { Litorâneas }\end{array}$ & Faz. São Joaquim & $-22,44$ & $-42,62$ & 275 & 2927,13 & 0,49 \\
\hline 54 & $\begin{array}{l}\text { Baixadas } \\
\text { Litorâneas }\end{array}$ & Gaviões & $-22,55$ & $-42,55$ & 1620 & 2526 & 0,1 \\
\hline 55 & $\begin{array}{l}\text { Baixadas } \\
\text { Litorâneas }\end{array}$ & Japuíba & $-22,56$ & $-42,70$ & 50 & 1831,07 & 0,2 \\
\hline 56 & $\begin{array}{l}\text { Baixadas } \\
\text { Litorâneas }\end{array}$ & Quarteis & $-22,46$ & $-42,31$ & 58 & 2342,42 & 0,1 \\
\hline 57 & $\begin{array}{l}\text { Baixadas } \\
\text { Litorâneas }\end{array}$ & Rio Dourado & $-22,48$ & $-42,09$ & 12 & 2137,03 & 0,1 \\
\hline 58 & $\begin{array}{l}\text { Baixadas } \\
\text { Litorâneas }\end{array}$ & Tanguá & $-22,71$ & $-42,70$ & 40 & 1773,02 & 22,41 \\
\hline 59 & Metropolitana & Ecologia Agrícola & $-22,77$ & $-43,68$ & 33 & 1429,11 & 14,81 \\
\hline 60 & Metropolitana & Alto da Boa Vista & $-22,95$ & $-43,27$ & 347 & 1751,52 & 2,96 \\
\hline 61 & Metropolitana & Bangu & $-22,87$ & $-43,45$ & 40 & 1350,69 & 8,88 \\
\hline 62 & Metropolitana & Benfica & $-22,89$ & $-43,25$ & 2 & 1649,09 & 7,4 \\
\hline 63 & Metropolitana & Campo Grande & $-22,92$ & $-43,54$ & 18 & 1393,28 & 7,6 \\
\hline 64 & Metropolitana & Eletrobrás & $-22,92$ & $-43,42$ & 40 & 1352,51 & 8,39 \\
\hline 65 & Metropolitana & $\begin{array}{c}\text { Elevatória de } \\
\text { Copacabana }\end{array}$ & $-22,98$ & $-43,19$ & 10 & 1598,42 & 23,2 \\
\hline 66 & Metropolitana & $\begin{array}{l}\text { Est. Bomba de } \\
\text { Imunana }\end{array}$ & $-22,68$ & $-42,95$ & 10 & 1418,92 & 0,59 \\
\hline 67 & Metropolitana & Frei Caneca & $-22,91$ & $-43,20$ & 20 & 1378,1 & 14,61 \\
\hline 68 & Metropolitana & Irajá & $-22,83$ & $-43,33$ & 6 & 1354,68 & 8,79 \\
\hline 69 & Metropolitana & Manuel Ribeiro & $-22,91$ & $-42,73$ & 5 & 1402,52 & 0,89 \\
\hline 70 & Metropolitana & Mendanha & $-22,86$ & $-43,54$ & 10 & 1772,51 & 8,39 \\
\hline 71 & Metropolitana & Faz. da Lapa & $-22,85$ & $-44,00$ & 520 & 1350,28 & 6,52 \\
\hline 72 & Metropolitana & Represa Paraíso & $-22,50$ & $-42,91$ & 60 & 2787,05 & 0,39 \\
\hline 73 & Médio Paraíba & Barra Mansa & $-22,54$ & $-44,18$ & 376 & 1342,28 & 1,28 \\
\hline 74 & Médio Paraíba & Faz. Agulhas Negras & $-22,34$ & $-44,59$ & 1460 & 2558,61 & 0,3 \\
\hline 75 & Médio Paraíba & Faz. Sta Rosa & $-22,69$ & $-43,87$ & 421 & 1674,21 & 15,89 \\
\hline
\end{tabular}




\begin{tabular}{|c|l|c|c|c|c|c|c|}
76 & Médio Paraíba & Fumaça & $-22,30$ & $-44,31$ & 720 & 1921,03 & 0 \\
\hline 77 & Médio Paraíba & Glicério & $-22,47$ & $-44,23$ & 390 & 1321,81 & 0,2 \\
\hline 78 & Médio Paraíba & Ipê & $-22,70$ & $-43,87$ & 425 & 1630,2 & 15,7 \\
\hline 79 & Médio Paraíba & Itatiaia & $-22,50$ & $-44,55$ & 380 & 1591,85 & 0 \\
\hline 80 & Médio Paraíba & Lídice & $-22,83$ & $-44,19$ & 554 & 1843,15 & 0,59 \\
\hline 81 & Médio Paraíba & Nhangapi & $-22,50$ & $-44,62$ & 440 & 1348,24 & 0 \\
\hline 82 & Médio Paraíba & N.S do Amparo & $-22,39$ & $-44,11$ & 400 & 1769,9 & 0 \\
\hline 83 & Médio Paraíba & Ponte do Souza & $-22,27$ & $-44,43$ & 950 & 2218,47 & 0,1 \\
\hline 84 & Médio Paraíba & Resende & $-22,48$ & $-44,45$ & 440 & 1588,87 & 5,13 \\
\hline 85 & Médio Paraíba & $\begin{array}{c}\text { Ribeirão de São } \\
\text { Joaquim }\end{array}$ & $-22,47$ & $-44,23$ & 620 & 1438,2 & 0 \\
\hline 86 & Médio Paraíba & Sítio das Palmeiras & $-22,45$ & $-44,30$ & 390 & 1558,97 & 8,09 \\
\hline 87 & Médio Paraíba & $\begin{array}{c}\text { Usina Elevatório de } \\
\text { Vigário }\end{array}$ & $-22,63$ & $-43,90$ & 369 & 1571,46 & 6,61 \\
\hline 88 & Médio Paraíba & Vargem - Ralo & $-22,77$ & $-44,09$ & 510 & 1636,34 & 0,39 \\
\hline 89 & Médio Paraíba & Visconde de Mauá & $-22,33$ & $-44,54$ & 1030 & 1220,62 & 0,49 \\
\hline 90 & Médio Paraíba & Piraí & $-22,63$ & $-43,88$ & 388 & 1606,95 & 23,69 \\
\hline 91 & Médio Paraíba & Volta Redonda & $-22,50$ & $-44,09$ & 360 & 1499,94 & 0,49 \\
\hline 92 & Médio Paraíba & Conservatória & $-22,29$ & $-43,93$ & 550 & 1585,59 & 0 \\
\hline 93 & Médio Paraíba & $\begin{array}{r}\text { Elevatório Santa } \\
\text { Cecília }\end{array}$ & $-22,48$ & $-43,84$ & 371 & 1589,98 & 0 \\
\hline 94 & Médio Paraíba & Faz. São Francisco & $-22,34$ & $-43,81$ & 690 & 1549,3 & 11,75 \\
\hline 95 & Médio Paraíba & Manuel Duarte & $-22,09$ & $-43,56$ & 396 & 1309,03 & 0,99 \\
\hline 96 & Médio Paraíba & Pentagna & $-22,16$ & $-43,76$ & 497 & 1623,85 & 0,79 \\
\hline 97 & Médio Paraíba & $\begin{array}{c}\text { Santa Isabel do Rio } \\
\text { Preto }\end{array}$ & $-22,23$ & $-44,06$ & 544 & 1608,18 & 0,3 \\
\hline 98 & Médio Paraíba & Taboas & $-22,21$ & $-43,62$ & 444 & 1487,95 & 1,18 \\
\hline 99 & Médio Paraíba & Valença & $-22,22$ & $-43,70$ & 549 & 1155,92 & 0,1 \\
\hline
\end{tabular}




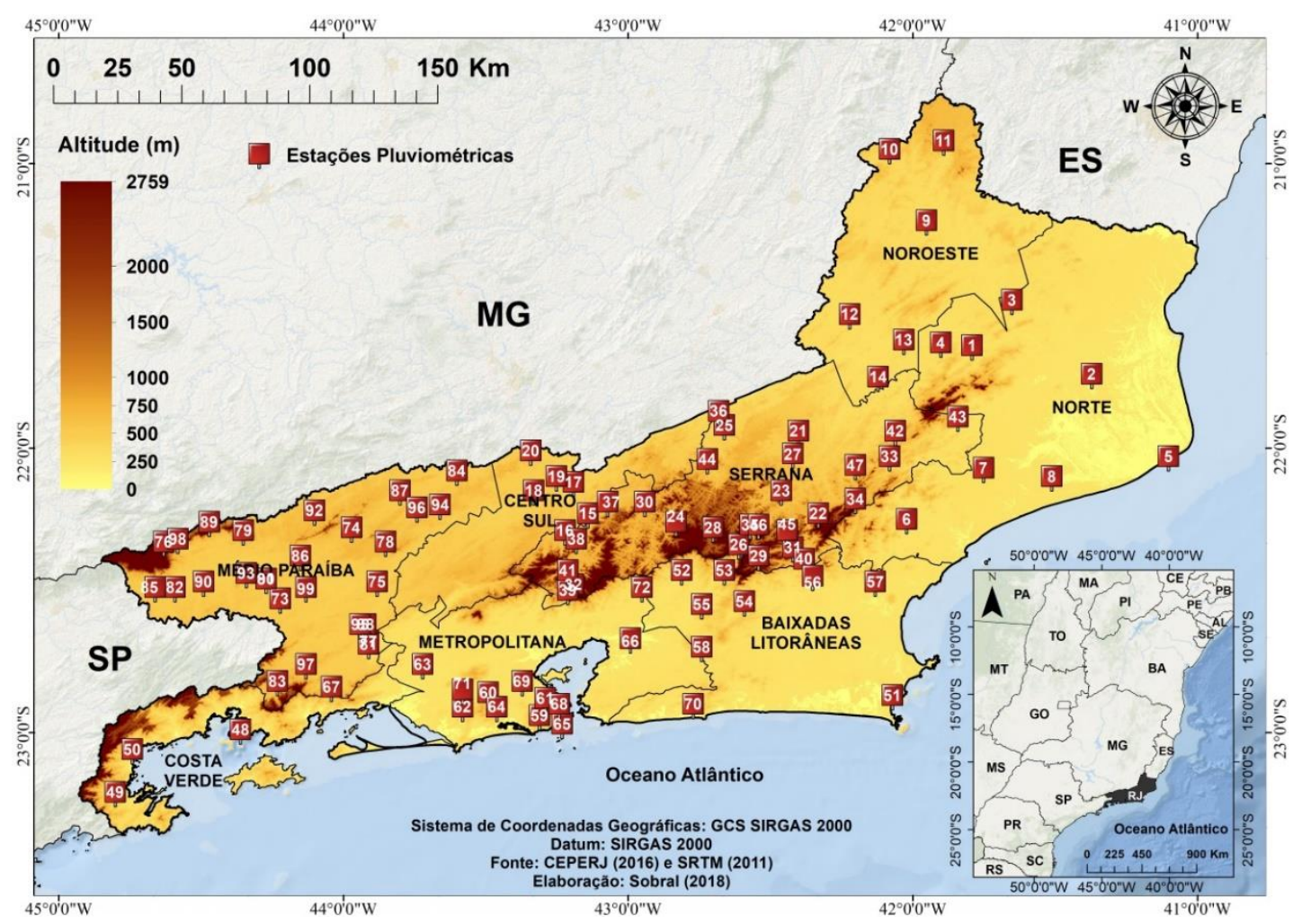

Figura 2 - Localização das estações pluviométricas, meteorológicas convencionais e automáticas e a hipsometria $(\mathrm{m})$ do Rio de Janeiro.

\subsection{PREENCHIMENTOS DAS FALHAS DA SÉRIE TEMPORAL DE CHUVA}

Conforme a Tabela 1 apresentada, as séries temporais de chuva de 79\% das estações utilizadas apresentaram algum tipo de falha nos registros. As regiões de Governo com os maiores percentuais médios de falhas registradas entre 1979 e 2009 foram Metropolitana (8,10\%), Costa Verde (7,63\%) e Baixadas Litorâneas $(6,41 \%)$, todas localizadas na costa oceânica do ERJ; seguidas das regiões Centro Sul (6,33\%), Médio Paraíba (3,48\%), Norte $(2,31 \%)$, Serrana $(1,58 \%)$ e Noroeste $(1,00 \%)$. Destaca-se o baixo percentual de falhas identificado nas séries temporais de chuva deste trabalho, de maneira que os resultados apresentados no item 3 estão majoritariamente embasados em dados estocásticos registrados nas diferentes estações.

Ainda assim, toda série temporal com falha foi preenchida com dados do satélite Tropical Rainfall Measuring Mission (TRMM, 2014) via produto 3B43 e das normais climatológicas proveniente do Instituto Nacional de Meteorologia (INMET). O produto 3B43 foi usado no período de 1998 a 2009 e as normais climatológicas do INMET no período 1979 a 1997 . Foram identificadas as estações melhores correlacionadas, estas foram então utilizadas para que se obtivesse o valor da chuva mensal esperado para uma dada estação com falha de dados durante esse período. Em seguida, foi aplicado o modelo de regressão linear simples (MRLS) entre os valores mensais observados de cada estação e o valor esperado obtido ( $r>0,70)$ das estações (BRITO et al., 2016). 
O produto 3B43 foi obtido no formato Network Common Data Form (NetCDF). Este produto fornece dados com resolução espacial de aproximadamente $30 \mathrm{~km}$ e resolução temporal mensal. Após a obtenção do produto 3B43, o mesmo foi convertido no software ArcGIS versão $10.1 \circledR$. Os dados foram registrados originalmente em $\mathrm{mm} \cdot \mathrm{h}^{-1}$, depois foram convertidos para acumulados mensais ( $\mathrm{mm} . \mathrm{mês}^{-1}$ ), técnica essa usada no ERJ por OliveiraJúnior et al. (2014) e em outras regiões do país como, por exemplo, no trabalho de Almeida et al. (2015) aplicado para o estado do Amazonas.

A seleção dos pontos do TRMM foi feita baseado na proximidade das estações dentro da região de estudo. No software ArcGIS 10.1 foi utilizado o ArcToolbox - Multidimension Tools, e as ferramentas de conversão Make NetCDF Raster Layer e Make NetCDF Table View para o procedimento.

\subsection{PROCEDIMENTOS DE ANÁLISE DOS DADOS}

Após, o preenchimento das falhas da série temporal pluviométrica foi aplicada estatística descritiva para obtenção dos parâmetros de média $(\mathrm{mm})$, desvio padrão $(\mathrm{mm})$, coeficiente de variação $(\%)$ e percentual de falhas. A análise exploratória (boxplot) foi realizada com ênfase aos valores discrepantes (outliers), enquanto a série temporal pluviométrica foi avaliada nas seguintes escalas: i) espacial - com intuito de avaliar a dinâmica da chuva e a sua interação com a complexa topografia e os sistemas meteorológicos do ERJ, ii) mensal - identificação dos totais mensais para cada uma das regiões de Governo do Rio de Janeiro, seguida da avaliação dos fatores fisiográficos e dinâmicos que atuam em cada região, bem como o destaque para meses chuvosos e secos e, por fim, iii) interanual - identificação dos totais anuais para cada região do ERJ, seguida da associação com os sistemas meteorológicos de diversas escalas (local a sinótica) e o modo de variabilidade climática El NiñoOscilação Sul (ENOS).

\section{RESULTADOS E DISCUSSÃO}

\subsection{DISTRIBUIÇÃO ESPACIAL DA CHUVA NA ESCALA ANUAL}

O ERJ está localizado na zona R5, conforme Reboita et al. (2010), que abrange grande parte da América do Sul (AS), desde Equador e norte do Peru até a região Sudeste do Brasil. O total anual de chuva no Sudeste é de cerca de $1500 \mathrm{~mm}$. O Sudeste tem como principal característica ser uma região úmida no verão, devido ao sistema de monção da AS (Vera et al., 2006b), e seca no inverno (REBOITA et al., 2010). Segundo Reboita et al. (2010), nas regiões Sudeste e Centro-Oeste do Brasil, o escoamento de noroeste (NW) do Jato de Baixo Nível (JBN) pode convergir com o de nordeste (NE) induzido pela circulação do ASAS e, ainda com os alísios de NE, com isso há formação de uma banda de nebulosidade e intensificação da chuvas nestas regiões (Lenters e Cook, 1995) e, por fim a formação/intensificação da ZCAS, principalmente no verão (KOUSKY, 1988; KODAMA, 1992).

No período de estudo, a região com maior total pluviométrico anual médio registrado foi à região da Baixadas Litorâneas (2144 mm). Isso se deve, em grande parte, as estações que estão localizadas na vertente da cadeia montanhosa voltada para o oceano Atlântico, seguido da proximidade do 
ambiente costeiro (BRITO et al., 2016). Portanto, ambos os fatores fisiográficos juntamente com os sistemas meteorológicos que nela atuam, tais como a circulação de brisas marítima/terrestre e de baías, passagem de sistemas frontais (SF), posição migratória da ASAS e episódios de ZCAS (NIMER, 1972; DAVIS;NAGHETTINI, 2000; KELLER FILHO et al., 2005; BRITO et al., 2016; OLIVEIRA-JÚNIOR et al., 2017) interagem entre si e contribuem para que a região possua os maiores totais de chuva no ERJ.

A região da Costa Verde foi a segunda com maior chuva anual no ERJ (1912 mm), com 15,48\% do total de chuva no estado. De acordo com Nimer (1989), existem diversos fatores que contribuem para a magnitude e a distribuição da chuva nesta região. Dentre os fatores estáticos, relacionados às condições geográficas da área, destacam-se: i) a posição latitudinal, que propicia melhores condições à evaporação, pois a zona tropical recebe maior quantidade de radiação solar; ii) a posição na borda ocidental do oceano, pois a existência de superfícies líquidas é outra pré-condição do processo de evaporação; e iii) a topografia bem acidentada orientada no sentido oestesudoeste/leste-nordeste (WSW/ENE), com isso aumenta a turbulência do ar, pela ascendência orográfica, principalmente durante a passagem de perturbações atmosféricas (SOARES; NUNES; SENNA, 2014).

Em relação aos fatores dinâmicos que afetam a chuva na região, ainda segundo Soares et al. (2014), os principais são: 1) a atuação do ASAS, que durante o inverno migra para o Sudeste do Brasil (Reboita et al., 2010), inibindo movimentos ascendentes do ar, e portanto, a formação de nuvens e chuva; 2) os eventos causadores de chuva como a ZCAS, os SF, as Linhas de Instabilidade (LI), os Complexos Convectivos de Mesoescala (CCM) e as circulações das brisas. A circulação local promovida pelas brisas fornece umidade extra para outros sistemas e pode vir a intensificar a chuva na região da Costa Verde (MORALES et al., 2010; PEREIRA FILHO et al., 2002).

As regiões que registraram chuva abaixo da média para o ERJ (1.543 $\mathrm{mm}$ ) foram as regiões Norte $(1032 \mathrm{~mm})$ e Noroeste Fluminense $(1235 \mathrm{~mm})$, seguidas da região Centro Sul $(1307 \mathrm{~mm})$. De acordo com André et al. (2008), as regiões Norte e Noroeste estão localizadas a sotavento da Serra do Mar, favorecendo a compressão na baixa troposfera por ocasião das penetrações de escoamento de SW, que são os principais mecanismos de formação de chuva na região. Machado et al. (2010) identificaram que entre a região da Serra do Mar e a costa litorânea ocorre um aumento na magnitude da chuva, com uma alta variabilidade espacial. Esse comportamento é provavelmente causado pelo efeito orográfico.

Segundo Brito (2014), em seu modelo teórico-conceitual, a variação pluviométrica nas diferentes regiões de governo do ERJ sofre ação não só da influência dos principais sistemas sinóticos que atuam na região Sudeste (SF, ZCAS, ASAS e Bloqueio Atmosférico-BA), mas das características locais como a proximidade do ambiente costeiro e topografia complexa (regiões montanhosas que se contrastam com as planícies), formando regimes de circulação local. Essas características locais podem induzir a formação de chuva orográfica, chuva convectiva, regime de chuva produzida pelas circulações de brisa vale/montanha, lacustre/baía e marítima/terrestre, além de interagir e intensificar as LI, os SF e CCM (BRITO, 2014). 
A Serra dos Órgãos e os demais maciços rochosos, principalmente aqueles localizados nas regiões Metropolitana $(1570,62 \mathrm{~mm})$, Costa Verde $(1911,79 \mathrm{~mm})$, Médio Paraíba $(1601,89 \mathrm{~mm})$ e Serrana $(1546,51 \mathrm{~mm})$ mostraram influência marcante sobre o total anual de chuva, sendo identificado anteriormente por Machado et al. (2010). As estações meteorológicas localizadas ou próximas à vertente destes maciços voltada para o oceano Atlântico registraram grande volume médio anual no período. A sobreposição das camadas de topografia via Modelo Digital de Elevação (MDE) da SRTM e chuva média anual (Figura 5 ) revelaram elevadas ocorrências de chuvas próximas às regiões de Serra no ERJ, isso corrobora com Nimer (1972), a respeito da influência dos Maciços Litorâneos no regime pluviométrico do estado, por meio de chuvas orográficas.

Este tipo de chuva incide nas áreas à barlavento da Serra do Mar e da Mantiqueira, quando por efeito de mudança brusca do relevo, ocorrem chuvas intensas e de curta duração. De acordo com Smith e Barstad (2004), o efeito orográfico local contribui para o aumento de umidade e, consequentemente, maior probabilidade de chuva com maior intensidade. Este efeito é corroborado por André et al. (2008), em estudo que utilizou a técnica de análise de agrupamento (AA) aplicada ao ERJ, obtendo seis regiões pluviometricamente homogêneas. Novamente, neste trabalho, as maiores médias de chuva mensal foram registradas nas estações próximas das Serras do Mar e da Mantiqueira. Este resultado corrobora ainda com os resultados obtidos por Brito (2014), onde a região limitada pela Serra do Mar em direção ao interior do estado não apresentou grande variabilidade no máximo de chuva anual se comparado à região da Serra do Mar em direção ao litoral, que recebe maior quantidade de umidade proveniente do Oceano Atlântico.

A Tabela 2 apresenta um resumo da estatística descritiva aplicada para cada região de Governo do ERJ. Considerando o desvio padrão (DP) calculado para as diferentes regiões do ERJ, pode-se inferir que as regiões Baixadas Litorâneas $(2143,96 \pm 141,65 \mathrm{~mm})$ e Costa Verde $(1911,79 \pm 129,02 \mathrm{~mm})$ possuem variações pluviométricas similares quanto ao total anual de chuva. Este resultado se assemelha ao encontrado por Brito (2014) quanto à homogeneidade pluviométrica dessas regiões. O mesmo se aplica às regiões Médio Paraíba $(1601,89 \pm 121,44 \mathrm{~mm})$, Metropolitana $(1570,62 \pm 106,51 \mathrm{~mm})$ e Serrana $(1546,51 \pm 120,45 \mathrm{~mm})$. Neste caso, porém, os resultados de Brito (2014) mostram três regiões com regime pluviométrico independente e aparentemente sem correlação.

As regiões Noroeste e Centro Sul apresentaram totais anuais de chuva dentro do intervalo 1134,29 e $1410,65 \mathrm{~mm}$ se considerados os DP destas regiões. Já a região Norte permanece como a região com menor volume anual médio de chuva ainda que considerado o DP das diferentes regiões do ERJ. Ressaltam-se ainda os altos valores dos coeficientes de variância (CV) obtidos em cada região do ERJ, sendo a região Norte a que apresentou o maior valor do CV $(101,22 \%)$ e a região das Baixadas Litorâneas com o menor valor de CV $(79,28 \%)$; de maneira que quanto menor o CV maior é a precisão dos dados. Os altos valores de CV corroboram com Gois (2017) quanto ao fraco desempenho dos parâmetros estatísticos nas diferentes regiões do ERJ. 
Tabela 2 - Valores de chuva média anual acumulada $(\mathrm{mm})$, desvio padrão (DP, $\mathrm{mm}$ ), coeficiente de variância (CV, \%) e percentual (\%) nas diferentes regiões de Governo do estado do Rio de Janeiro entre 1979-2009.

\begin{tabular}{|c|c|c|c|c|}
\hline $\begin{array}{c}\text { Regiões de } \\
\text { Governo }\end{array}$ & $\begin{array}{c}\text { Chuva Média } \\
\text { Acumulada }(\mathbf{m m})\end{array}$ & $\begin{array}{c}\text { Desvio Padrão } \\
(\mathbf{m m})\end{array}$ & $\begin{array}{c}\text { CV } \\
\mathbf{( \% )}\end{array}$ & $\begin{array}{c}\text { Percentual } \\
\mathbf{( \% )}\end{array}$ \\
\hline Baixadas Litorâneas & 2143,96 & 141,65 & 79,28 & 17,36 \\
\hline Costa Verde & 1911,79 & 129,02 & 80,98 & 15,48 \\
\hline Médio Paraíba & 1601,89 & 121,44 & 90,97 & 12,97 \\
\hline Metropolitana & 1570,62 & 106,51 & 81,38 & 12,72 \\
\hline Serrana & 1546,51 & 120,45 & 93,46 & 12,52 \\
\hline Centro Sul & 1307,21 & 103,44 & 94,96 & 10,59 \\
\hline Noroeste & 1234,93 & 100,64 & 97,79 & 10,00 \\
\hline Norte & 1032,38 & 87,08 & 101,22 & 8,36 \\
\hline Média & $\mathbf{1 5 4 3 , 6 6}$ & $\mathbf{1 1 3 , 7 8}$ & $\mathbf{9 0 , 0 0}$ & \\
\hline
\end{tabular}

A Figura 3 ilustra a chuva média anual $(\mathrm{mm})$ de cada região de Governo do Estado do Rio de Janeiro com base na série temporal.

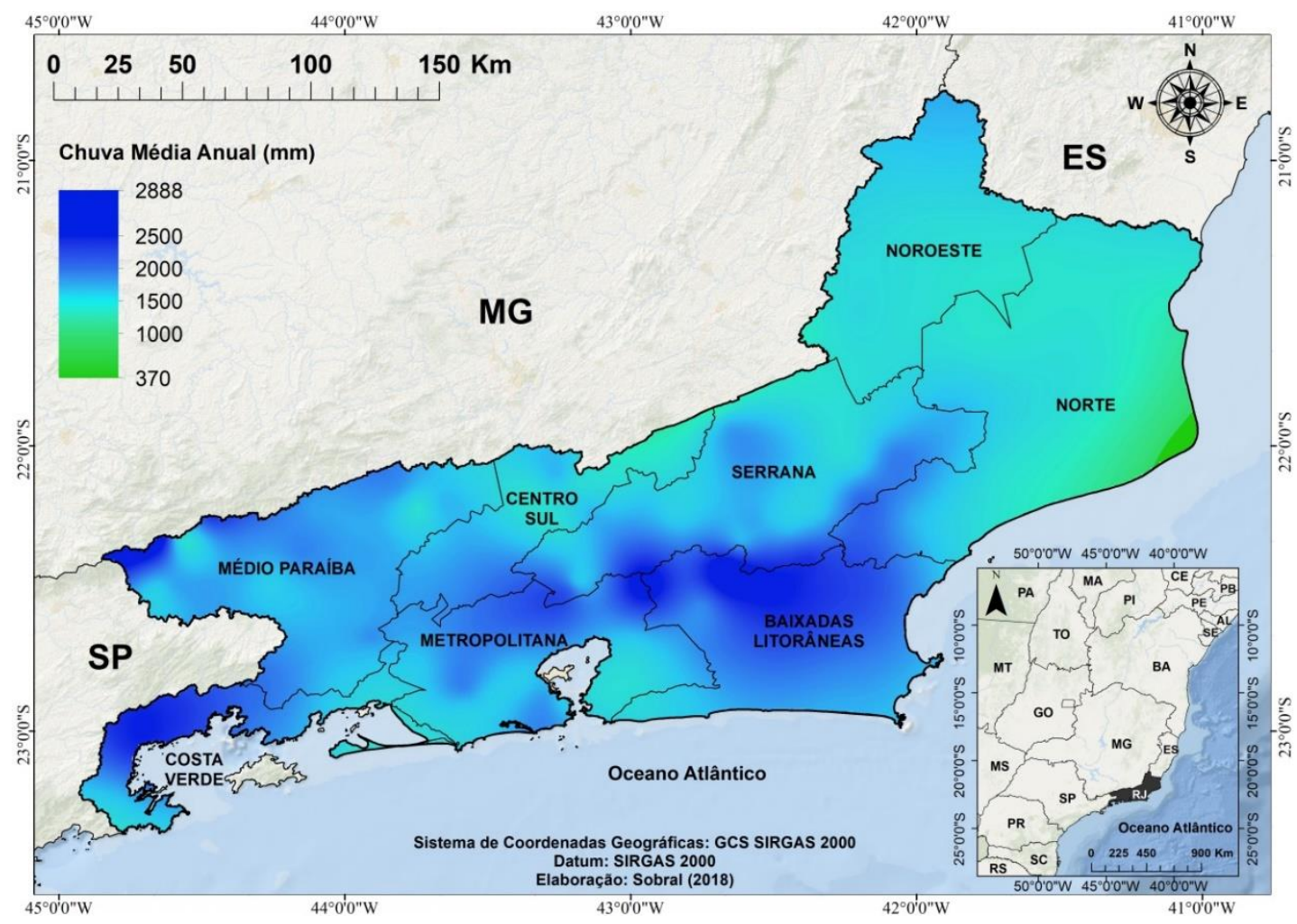

Figura 3 - Chuva anual média (mm) no período 1979-2009 para o estado do Rio de Janeiro. 
A Figura 4, apresenta o boxplot da chuva média anual nas regiões de Governo do ERJ, com base em parâmetros estatísticos descritivos do conjunto de dados da série temporal de 31 anos. Verifica-se que na região das Baixadas Litorâneas ocorreu o maior valor da mediana $(2122 \mathrm{~mm})$ e maior frequência de ocorrência da chuva média anual, no intervalo compreendido entre os valores de 1816 e 2388 mm. Na região Norte, a região mais seca do ERJ, o valor da mediana foi de $1069 \mathrm{~mm}$ e ocorreu o menor intervalo interquartil, entre todas as regiões de Governo do ERJ, com maior ocorrência dos valores entre 973 e $1152 \mathrm{~mm}$. Os outliers ocorreram em todas as regiões do ERJ e superaram 2500 mm nas regiões do Médio Paraíba, Metropolitana e Baixadas Litorâneas.

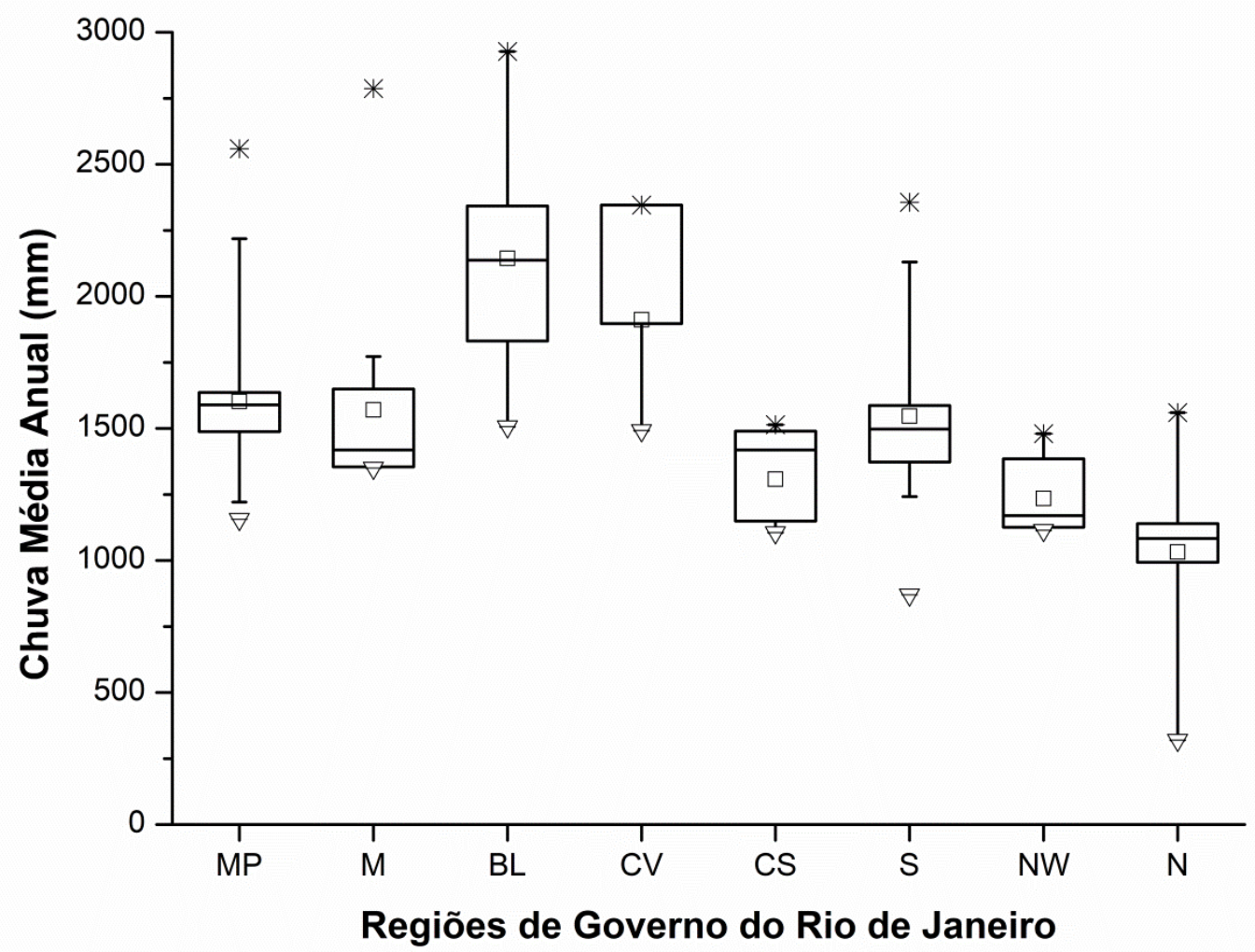

Figura 4 - Chuva anual média ( $\mathrm{mm}$ ) no período 1979-2009 nas regiões de Governo (MP - Médio Paraíba, M - Metropolitana, BL - Baixadas Litorâneas, CV - Costa Verde, CS Centro Sul, S - Serrana, NW - Noroeste e N - Norte) do estado do Rio de Janeiro.

\subsection{DISTRIBUIÇÃO DA CHUVA NA ESCALA MENSAL}

A chuva média mensal (Figura 5) para o ERJ mostrou que os meses de maio $(61 \mathrm{~mm})$, junho $(38 \mathrm{~mm})$, julho $(41 \mathrm{~mm})$, agosto $(42 \mathrm{~mm})$ e setembro (83 $\mathrm{mm}$ ) apresentaram os menores totais de chuva no período do estudo. Historicamente, são os meses de menor acúmulo de chuva no estado (NIMER, 1989; ANDRÉ et al., 2008; BRITO et al., 2016 ). Os dados apresentados referem-se ao período entre o final do outono, inverno e início da primavera como a época mais sujeita a diminuição do regime de chuva no ERJ, um dos 
motivos se deve a atuação da ASAS, que durante o inverno migra para o Sudeste do Brasil (REBOITA et al., 2010) inibindo movimentos ascendentes do ar, e portanto, a formação de nuvens e precipitação; seguido da atuação de BA comumente no inverno (MENDES et al., 2005), além da diminuição da frequência de atuação de SF (OLIVEIRA-JÚNIOR et al., 2014).

Ao considerar a média mensal do ERJ, os meses mais chuvosos foram dezembro (264 mm), janeiro $(247 \mathrm{~mm})$ e novembro (194 mm), que compreendem o período de transição entre as estações da primavera e do verão. Cabe ressaltar a importância dos sistemas meteorológicos na geração de chuvas no ERJ, com a ZCAS e os SF sendo os principais mecanismos formadores de chuva durante o verão (KODAMA, 1993a, 1993b; CARVALHO, 2002).

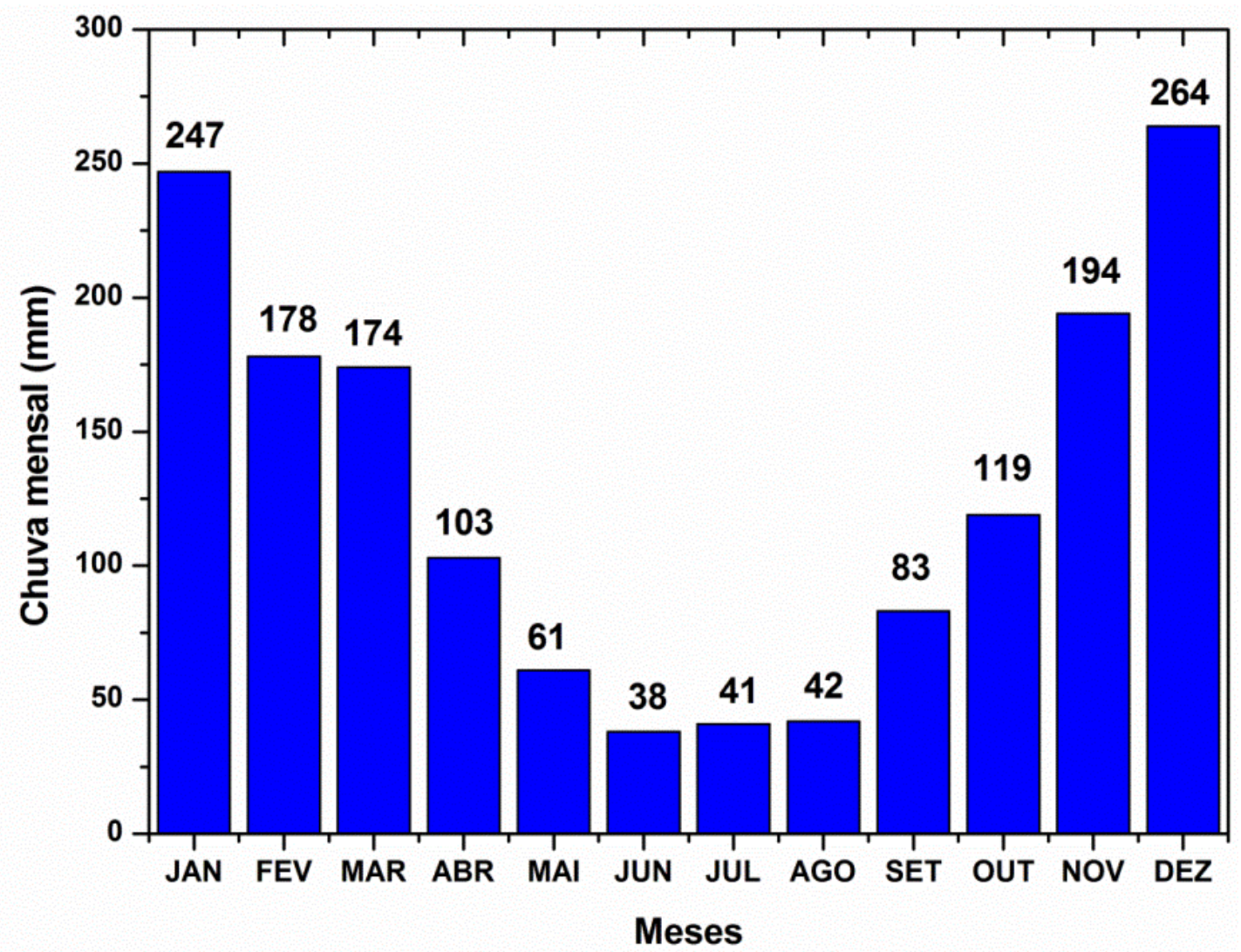

Figura 5 - Chuva média mensal (mm) no período de 1979-2009 para o estado do Rio de Janeiro.

Embora os valores médios caracterizem a sazonalidade do regime de chuvas no ERJ, buscou-se por meio da Figura 6 (a-h) apresentar de forma separada os registros mensais médios de chuva em cada região de Governo do ERJ. A Figura 6 (a-h) mostra que cinco regiões de Governo (Norte, Noroeste, Serrana, Centro Sul e Baixadas Litorâneas) apresentam regime pluviométrico similar no que tange a sua temporalidade. Independente dos diferentes fatores fisiográficos e dinâmicos que atuam em cada região, nestas regiões os meses mais chuvosos foram novembro, dezembro e janeiro enquanto os meses mais 
secos foram junho, julho e agosto. Os meses de junho, julho e agosto foram os meses com menor registro de chuva em todas as regiões do ERJ. Entretanto, as regiões Metropolitana e Médio Paraíba, localizadas na parte central e oeste do estado registraram dezembro, janeiro e fevereiro como os meses mais chuvosos. Já a região Costa Verde, localizada no extremo sudoeste do ERJ registrou nos meses de dezembro, janeiro e março os maiores totais de chuva.
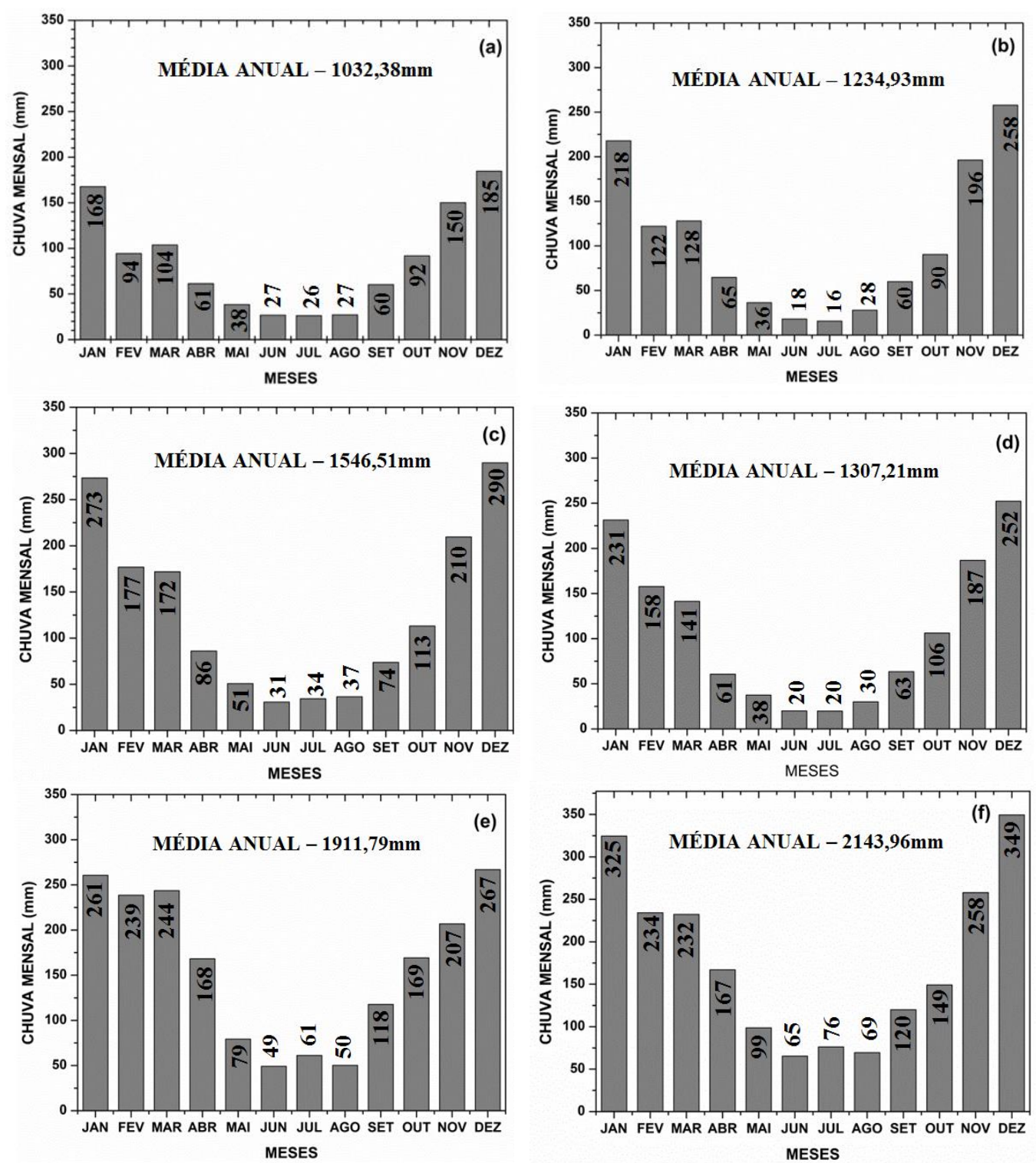

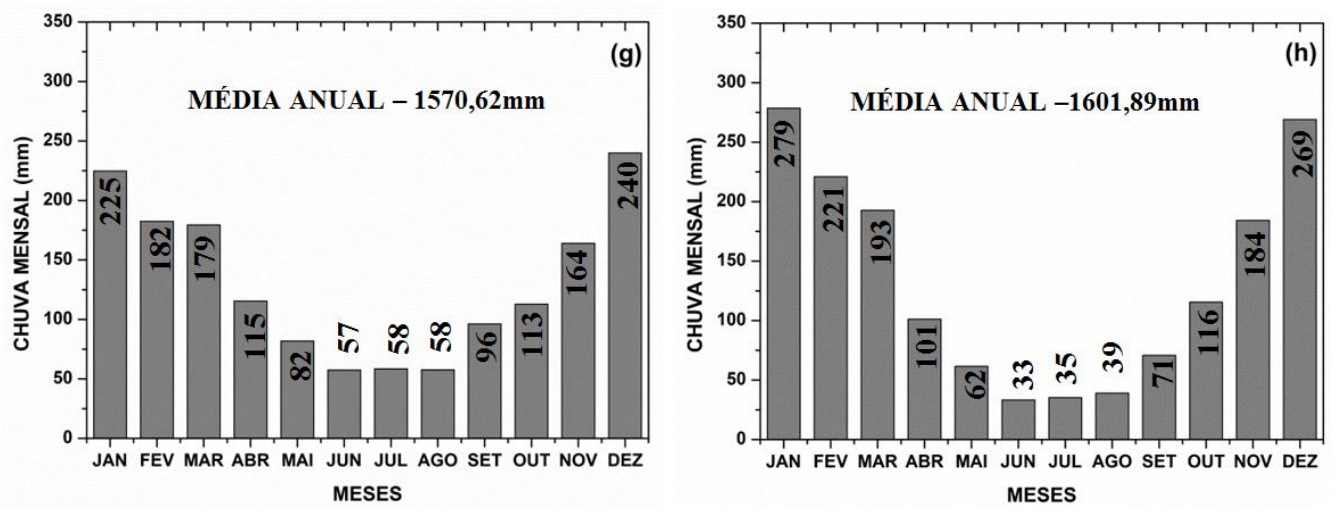

Figura 6 - Chuva média mensal $(\mathrm{mm})$ no período de 1979 a 2009 para as Regiões Norte (a), Noroeste (b), Serrana (c), Centro Sul (d), Costa Verde (e), Baixadas Litorâneas (f), Metropolitana (g) e Médio Paraíba (h).

\subsection{VARIABILIDADE PLUVIOMÉTRICA INTERANUAL}

Em relação à variabilidade interanual, os totais pluviométricos da região Baixadas Litorâneas ficaram abaixo da média $(2143 \mathrm{~mm}$ ) para a região em $70 \%$ do período de estudo, principalmente entre os anos de 1984 e 2003. Já a década de 2000 apresentou aumento na frequência de anos com chuva acima da média, com destaque para o período de 2004-2009, a exceção foi o ano de 2006. Na região Baixadas Litorâneas (Figura 7) foi possível identificar longo período de chuva abaixo da média entre 1979-1993, com exceção dos anos de 1983 (El Niño Muito Forte), 1985 (La Niña Fraca) e 1988 (La Niña Forte), segundo a literatura.

2006 - No início do ano a região Sudeste do país registrou chuvas abaixo da média, segundo boletim mensal Climanálise. No ERJ, foram registrados em março os maiores desvios negativos de chuva para toda a região. As chuvas ficaram abaixo da normal climatológica em praticamente toda a região no mês de abril, e o rápido deslocamento dos SF e maio também resultou em baixos valores de chuva na maior parte do mês. Somente em junho, com a passagem do segundo SF, a cidade do Rio de Janeiro (região Metropolitana) registrou chuvas mais intensas; o que não se repetiu necessariamente na região Baixadas Litorâneas. Os meses seguintes de julho, agosto e setembro também foram de chuva baixa na região Sudeste, cenário que só foi modificado no ERJ a partir de outubro (início do ano hidrológico), com os SF que se deslocaram durante a $2^{a}$ quinzena do mês e a formação da ZCAS. Em novembro, nos Estados de Minas Gerais, Espírito Santo e Rio de Janeiro, houve predominância de chuva acima da média; enquanto a atuação do quarto SF próximo ao litoral da Região Sudeste e a presença de VCAN, sobre o Nordeste do Brasil e oceano adjacente, favoreceram a formação de áreas de instabilidade, com temporais e ventos fortes sobre Rio de Janeiro, São Paulo e Minas Gerais (CPTEC, 2006). 


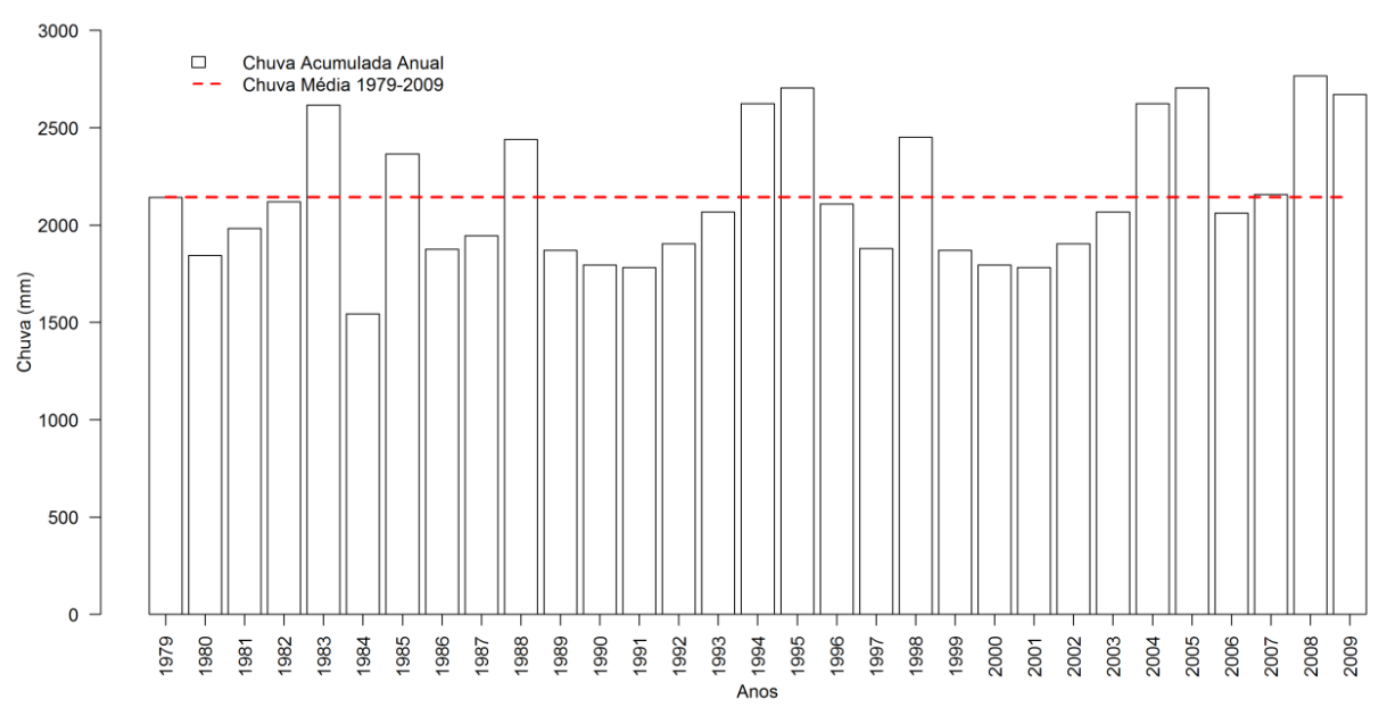

Figura 7 - Chuva acumulada anual e chuva média (mm) de 1979-2009 na Região Baixadas Litorâneas.

Similarmente, porém de forma menos acentuada, a região Costa Verde (Figura 8) a região Costa Verde apresentou o aumento significativo da frequência de anos chuvosos no período, com início a partir do final da década de 80 e meados da década de 90. A região Costa Verde tem índices pluviométricos anuais similares à região da Baixadas Litorâneas, isso se deve a proximidade do ambiente costeiro e a interação com a topografia complexa, visto que ambas as regiões de Governo possuem vertentes voltadas para o Oceano Atlântico, que por sua vez contribui para altas ocorrências pluviométricas (OLIVEIRA JÚNIOR et al., 2014; SOARES et al., 2014; BRITO et al., 2016). Diferentemente das chuvas convectivas registradas na região Centro Sul, estas regiões parecem ter o seu regime pluviométrico mais relacionado com a ocorrência de chuvas orográficas, que por efeito variação significativa do relevo provocam chuvas intensas e de curta duração (NIMER, 1972). 


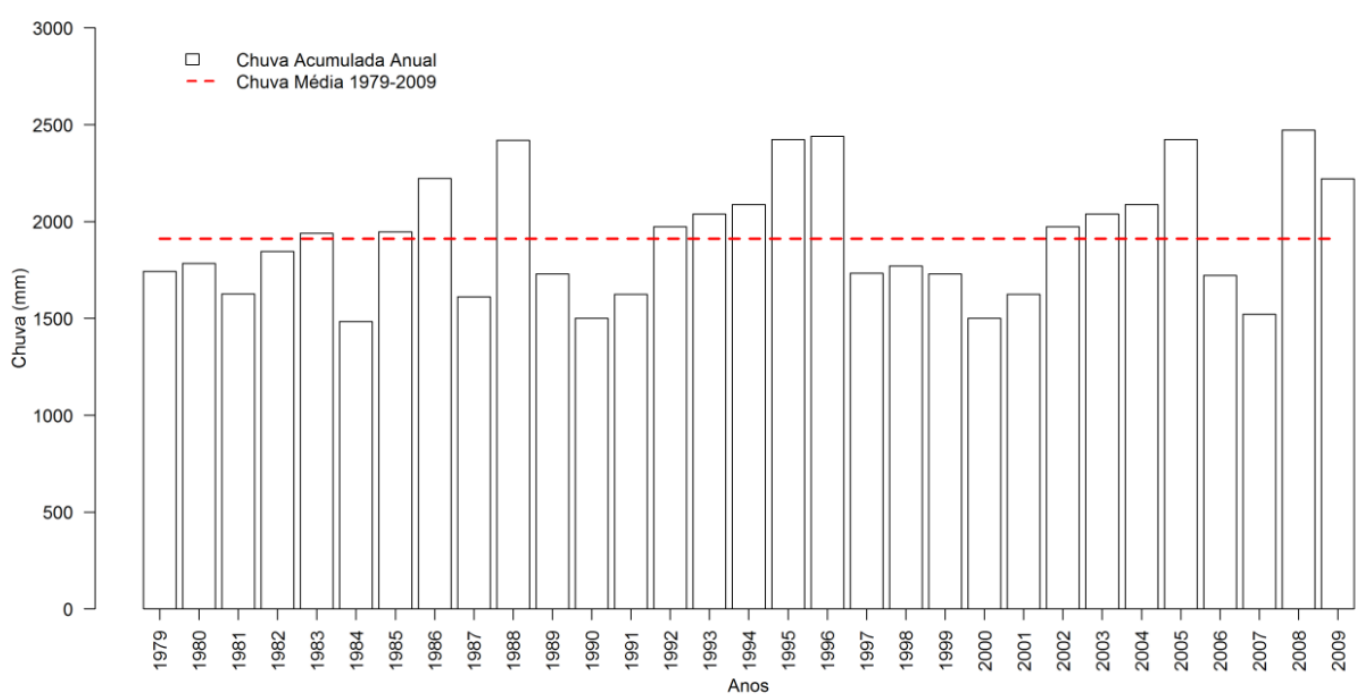

Figura 8 - Chuva acumulada anual e chuva média (mm) no período de 1979 a 2009 na Região Costa Verde do ERJ.

A região do Médio Paraíba (Figura 9) apresentou totais de chuva abaixo da média (1.601 mm) entre 1979-2003. Neste período, apenas oito anos (1982, 1983, 1985, 1986, 1988, 1994, 1995 e 1996) registraram chuva acima da média. O período entre 2004-2009 (exceto 2007) foi o de maior volume anual precipitado, similar à região das Baixadas Litorâneas. Nesta região, ora houve aumento ou redução de anos chuvosos. A região apresentou oscilação pluviométrica em todo o período do estudo, com anos secos e chuvosos se intercalando por toda a série temporal. Nos anos de 2006 e 2007, por exemplo, foi registrada baixa pluviometria em quase todas as regiões do ERJ, informação que foi corroborada pelo boletim Climanálise do CPTEC, parcialmente reproduzido a seguir:

2006 - As chuvas dos meses de janeiro, fevereiro e março ficaram abaixo da média em quase toda a Região Sudeste do Brasil. No mês de abril ficaram abaixo da normal climatológica no centro-sul do Rio de Janeiro. Os SF deslocaram-se rapidamente pela Região Sudeste nos meses de maio e junho, o que resultou em baixos valores de chuva na maior parte do mês. O mês de julho registrou normalidade pluviométrica, seguido de mais um mês com baixa ocorrência de chuva em praticamente toda a região Sudeste. Somente em outubro, novembro e dezembro deste ano foram registradas chuvas acima da média, ocasionadas por SF e ZCAS (CPTEC, 2006).

2007 - Neste ano, as chuvas ocasionadas por episódios de ZCAS foram registradas nos meses de janeiro e 
fevereiro, o mês de março foi de chuva baixa devido ao escoamento anticiclônico anômalo que se observou ao longo do mês, em baixos níveis, e o posicionamento de cavados e VCAN. Estes fenômenos climáticos contribuíram para a permanência de uma massa de ar seco em toda a região Sudeste do Brasil nos meses de março e abril. Em maio deste ano, a atuação dos SF foi maior nos Estados de São Paulo e Rio de Janeiro. Junho, julho, agosto e setembro foram meses com chuva abaixo da média histórica. No mês de outubro, apesar da ocorrência desses extremos, a chuva média mensal ficou abaixo da média climatológica na maior parte da Região Sudeste, com exceção do setor centro-norte do ERJ. Em dezembro, mais uma vez, chuvas ocorreram abaixo da média histórica em grande parte da Região Sudeste (CPTEC, 2007).

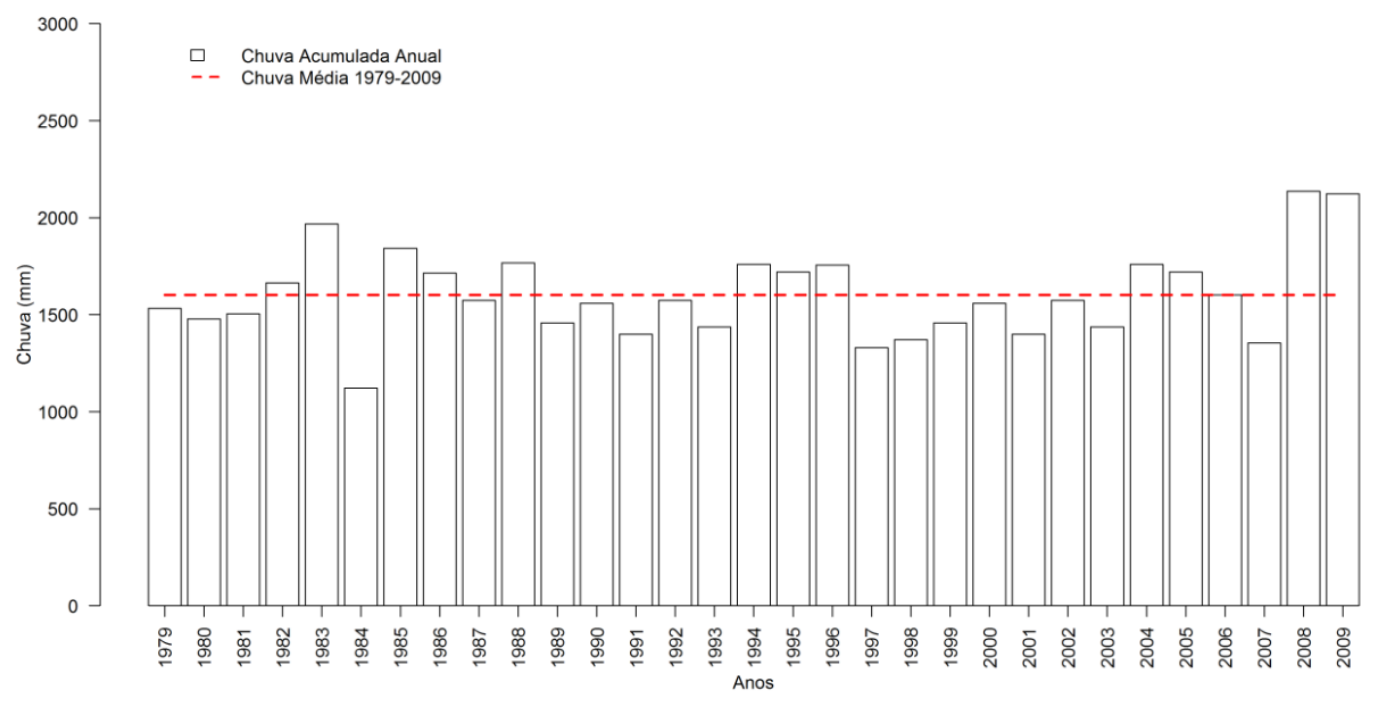

Figura 9 - Chuva acumulada anual e chuva média (mm) no período de 1979 a 2009 na Região Médio Paraíba do ERJ.

Regime pluviométrico similar à região Médio Paraíba foi identificado na região Metropolitana (Figura 10), que com $1570 \mathrm{~mm}$ de chuva média acumulada anualmente é a $4^{a}$ região mais chuvosa do ERJ, seguida da região Serrana (1546 mm). Cabe ressaltar a influência dos grandes maciços rochosos no regime pluviométrico da região Metropolitana, conforme apresentado por Dereczynski et al. (2009) em estudo que identificou os três maciços (Tijuca, Gericinó e Pedra Branca) da cidade do Rio de Janeiro (CRJ) como as regiões de maior acumulado pluviométrico em todo município. Tais maciços funcionam como centros dispersores de águas pluviais, as quais convergem naturalmente para os fundos de vales (CAMBRA e NETTO, 1997). 


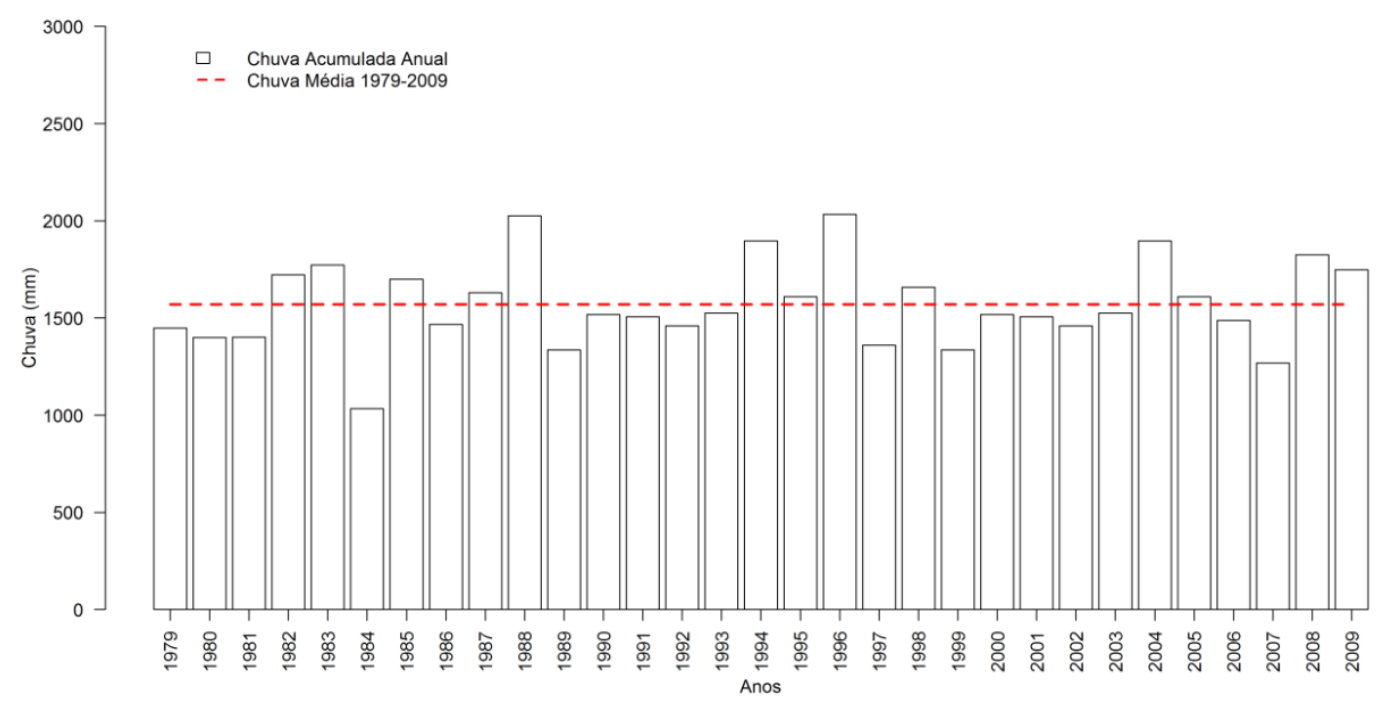

Figura 10 - Chuva acumulada anual e chuva média $(\mathrm{mm})$ para o período de 1979 a 2009 na Região Metropolitana do ERJ.

Com ocorrência de chuva próxima à média do ERJ $(1.543,66 \mathrm{~mm})$, a região Serrana com $1.547 \mathrm{~mm}$ de chuva média anual, apresentou alta ocorrência de anos secos consecutivos, principalmente entre 1986-1993. Se considerarmos o período consecutivo de 1986-2003 (18 anos), apenas os anos de 1994, 1995 e 1996 não registraram chuva abaixo da média anual. Considerando todo o período (1979-2009), a região Serrana (Figura 11) registrou mais de $60 \%$ dos anos da série temporal abaixo da média pluviométrica calculada para a região.

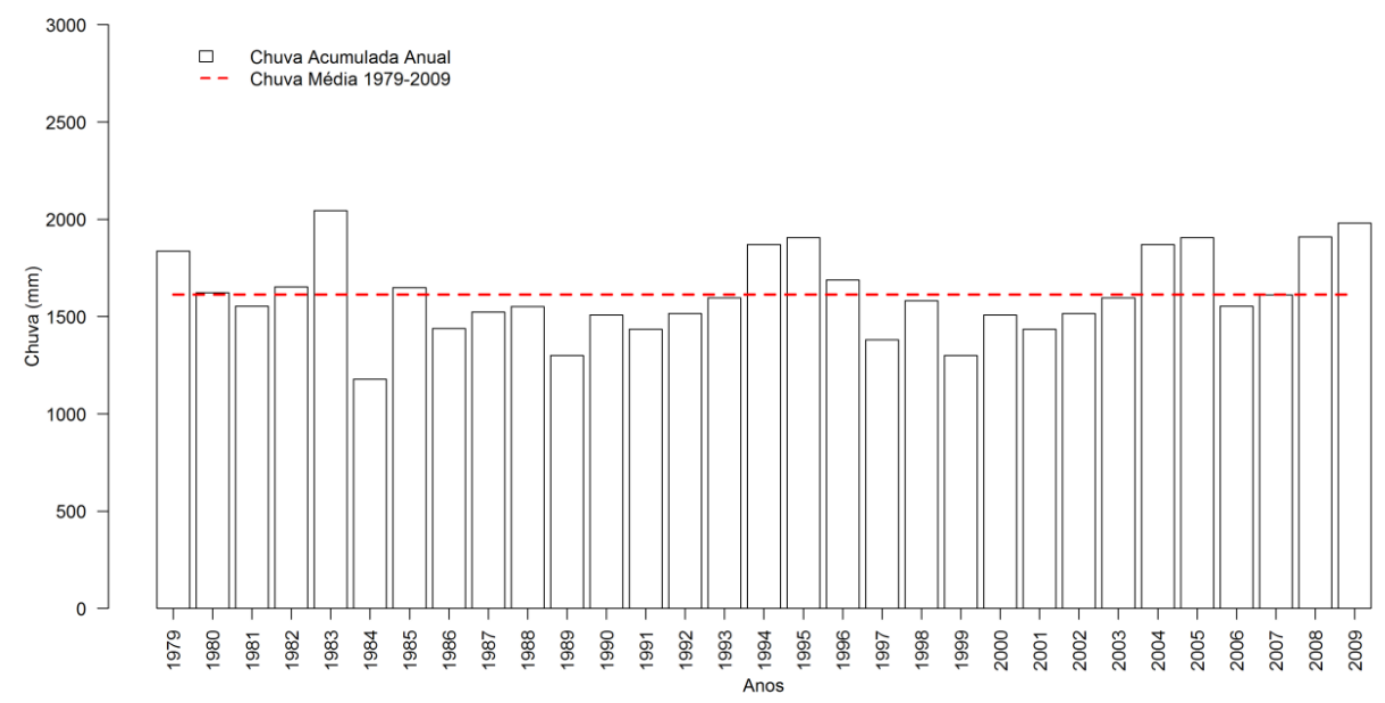

Figura 11 - Chuva acumulada anual e chuva média (mm) para o período de 1979 a 2009 na Região Serrana do ERJ. 
Com a terceira menor média $(1307 \mathrm{~mm}$ ) de chuva anual acumulada no ERJ, a região Centro Sul apresentou aumento significativo de anos com chuva acima da média, passando de $30 \%$ na década de 80 para $80 \%$ dos anos na década de 2000 (Figura 12). Na Figura 12, a caracterização do total pluviométrico precipitado na região Centro Sul é ilustrada, com destaque para a presença de oito anos chuvosos na década de 2000 (com exceção de 2000 e 2006). A região Centro Sul está localizada entre as Serras do Mar e da Mantiqueira, o que ajuda a explicar a $3^{a}$ menor média atrás das regiões Norte e Noroeste Fluminense, em virtude da influência da topografia complexa e dos sistemas meteorológicos que nela atuam (BRITO et al., 2016).

O aumento do total precipitado nos anos chuvosos pode ter relação com o aumento do grau de urbanização da região nas últimas décadas aumentando, portanto, as chuvas do tipo convectiva via intensificação da Ilha de Calor Urbano (ICU) (MORAES et al., 2005). Estas chuvas são potencializadas com a urbanização, sendo de curta duração, porém de alta intensidade e com baixa abrangência espacial (NIMER, 1972).

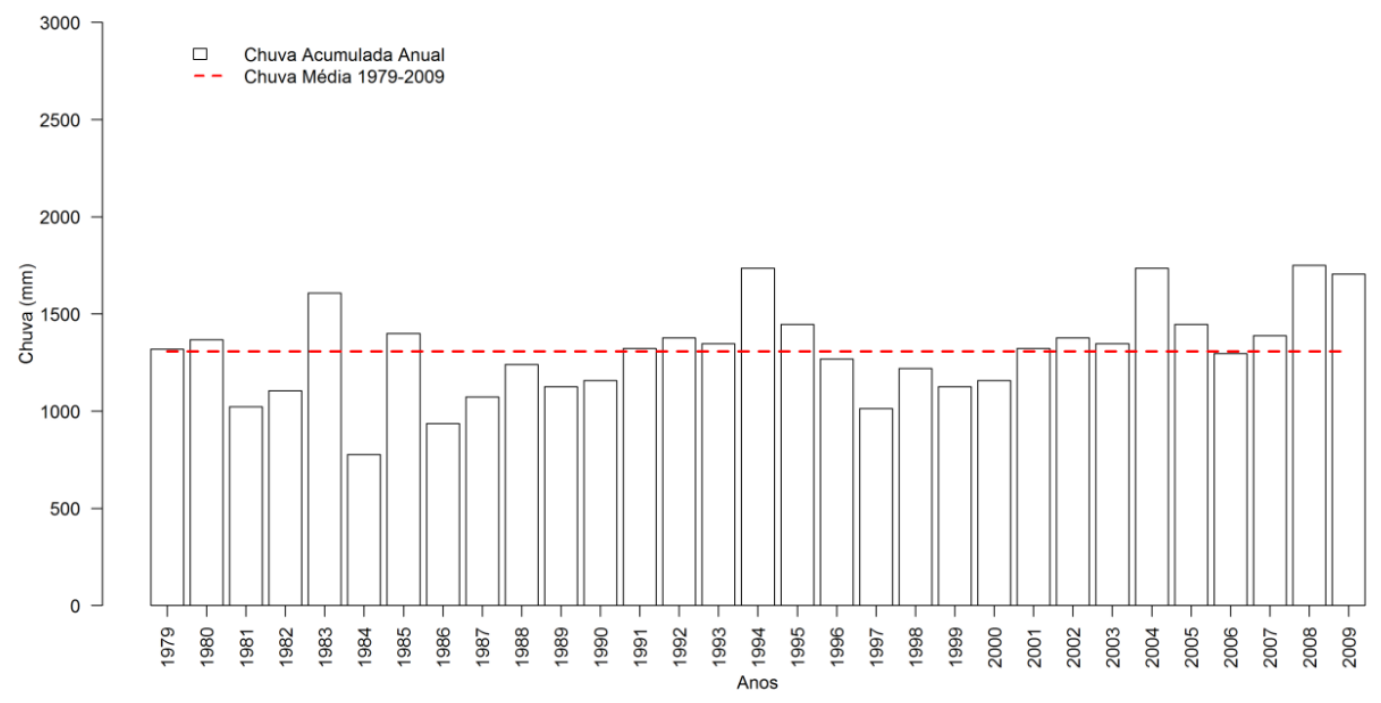

Figura 12 - Chuva acumulada anual e chuva média (mm) no período de 1979 a 2009 na Região Centro-Sul do ERJ.

Os registros de chuva acumulada na região Noroeste (Figura 13) são similares aos da região Norte (Figura 14), porém não são raros anos chuvosos em uma região e secos na outra, ocorrendo em $20 \%$ dos anos na série pluviométrica avaliada. O regime de chuva em tais regiões revela que na década de 1990 a região Noroeste reduziu em 25\% a frequência de anos com chuva acima da média, enquanto a região Norte teve um aumento em $150 \%$ dos anos com chuva total superior à média. 


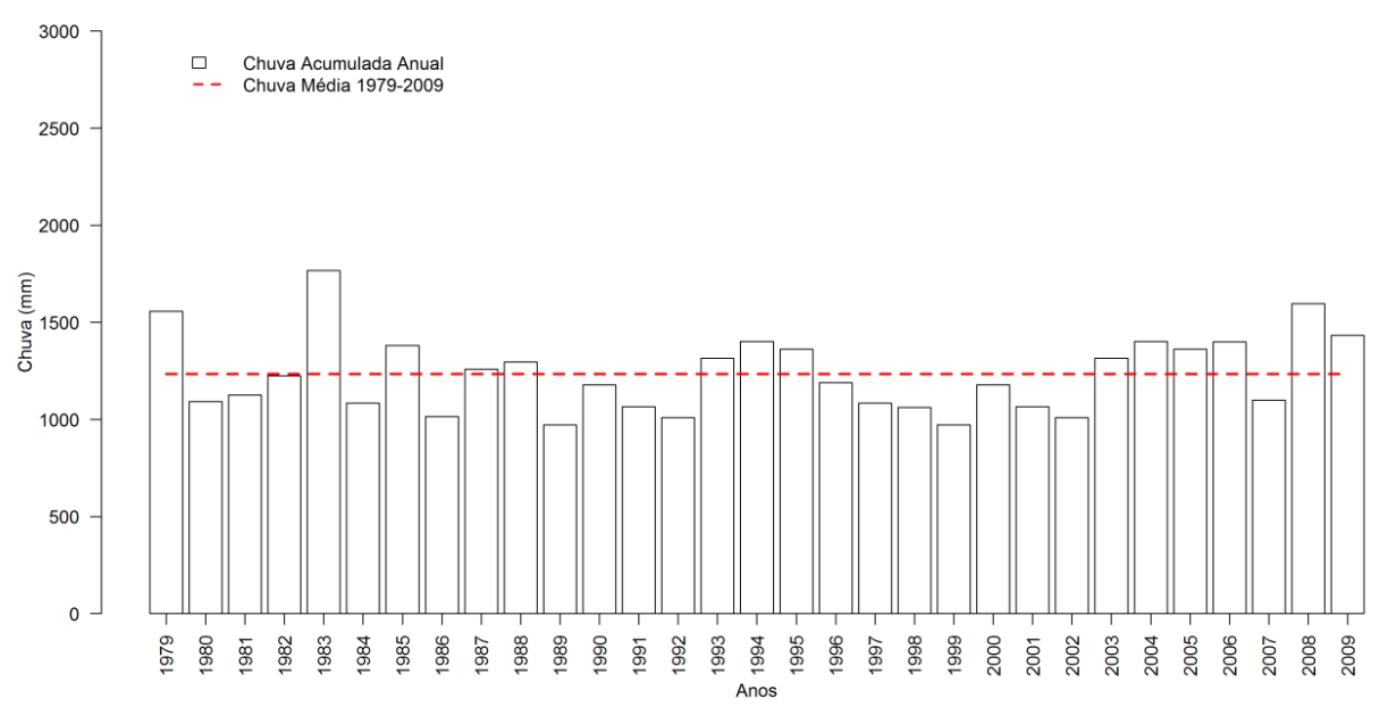

Figura 13 - Chuva acumulada anual e chuva média $(\mathrm{mm})$ para o período de 1979 a 2009 na Região Noroeste do ERJ.

De maneira geral, a região Norte revelou poucos períodos consecutivos de anos com chuva abaixo da média na série temporal. Os ciclos identificados na região Norte foram de até quatro anos consecutivos. Já a região Noroeste, registrou período de até sete anos consecutivos com chuva abaixo da média, entre 1996-2002. As duas regiões administrativas contam com as menores ocorrências pluviométricas do ERJ, sendo a média anual de chuva para a região Norte $1.032 \mathrm{~mm}$, enquanto para a região Noroeste a média anual é de 1.234 $\mathrm{mm}$. Este resultado está de acordo com André et al. (2008) no que tange o total de chuva acumulada anualmente em cada região do ERJ.

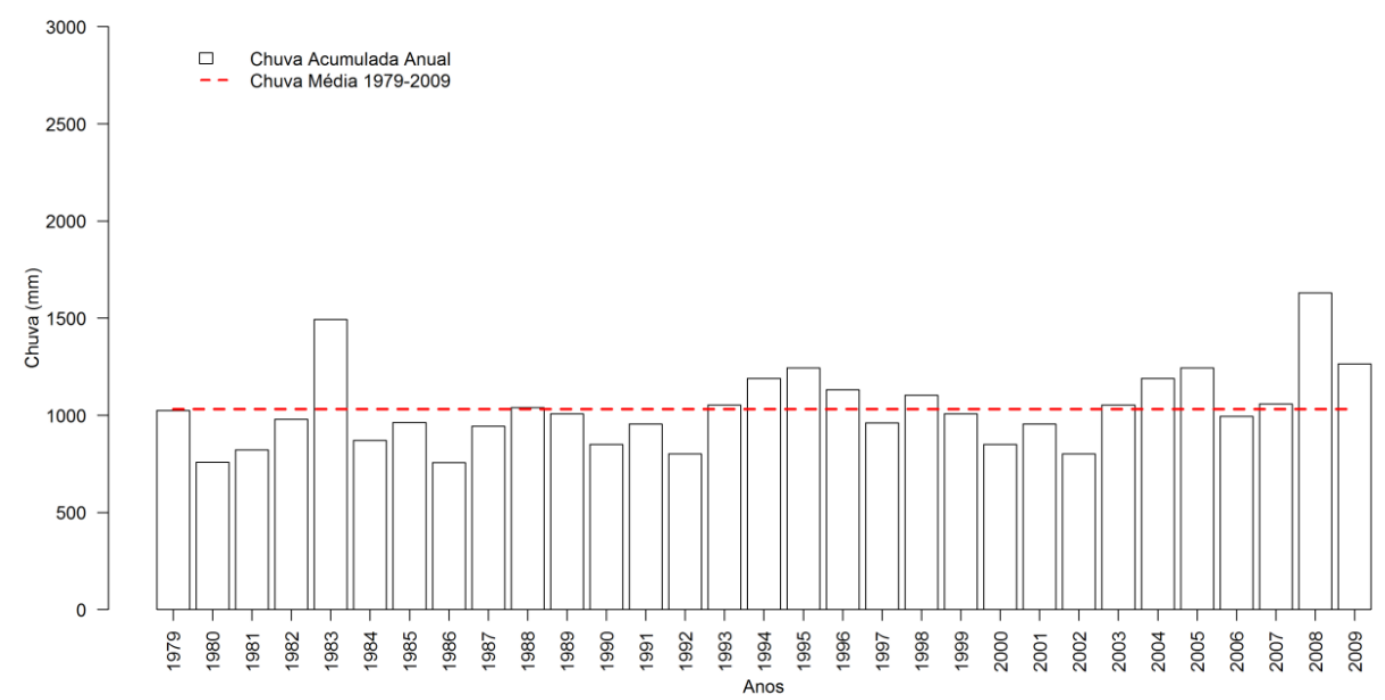

Figura 14 - Chuva acumulada anual e chuva média (mm) para o período de 1979 a 2009 na Região Norte do ERJ. 
As regiões Norte e Noroeste Fluminense, bem como a parte da região Centro Sul Fluminense localizada na Serra do Mar (voltada para o interior do continente) apresentam características pluviometricamente homogêneas. Essas regiões apresentaram os valores mais discrepantes - outliers (abaixo dos valores mínimos de chuva), com destaque para o menor regime de chuva dentre todos os grupos pluviometricamente homogêneos analisados no ERJ (BRITO et al., 2016). O regime de chuva das regiões Norte e Noroeste do ERJ são influenciados pelos mesmos sistemas meteorológicos atuantes sobre as regiões Serrana e Centro Sul Fluminense (Convecção local, SF, ZCAS, ASAS e BA), com exceção das circulações das brisas vale-montanha e com a atuação das circulações das brisas marítimas e terrestres (BRITO, 2014) e demais fatores de caráter dinâmico.

Nas regiões supracitadas a influência das circulações de brisas vale/montanhas são reduzidas devido à característica plana das regiões Noroeste e Norte Fluminense, da mesma forma que a proximidade maior com o Oceano Atlântico aumenta a concentração de umidade evaporada nessas regiões (NIMER, 1972). Ademais, a partir da latitude $22^{\circ} 00^{\prime \prime S}$, na direção Norte, os SF encontram-se menos úmidos, uma vez que, em caso de avanço dos mesmos, pelo eixo litorâneo, parte significativa dessa umidade é precipitada ao longo da sua trajetória na direção SW-NE (NIMER, 1989).

\section{CONSIDERAÇÕES FINAIS}

As principais conclusões deste estudo são referentes a espaçotemporalidade dos eventos chuvosos no estado do Rio de Janeiro. As regiões das Baixadas Litorâneas, Costa Verde, Médio Paraíba, Metropolitana e Serrana estão acima da média pluviométrica anual do estado, enquanto as regiões Centro Sul, Noroeste e Norte estão abaixo da média para o período de estudo. Considerando a significância estatística das médias pluviométricas calculadas, somente as regiões Baixadas Litorâneas e Costa Verde são classificadas como acima da média e as regiões Centro Sul, Noroeste e Norte permanecem abaixo da média. As demais regiões registraram chuva média acumulada dentro do intervalo de confiança (1426 a $1723 \mathrm{~mm}$ ) abrangido pela média e desvio padrão de cada região de Governo.

A análise da chuva média mensal mostra que os meses de junho, julho e agosto são, respectivamente, os meses de menor pluviometria em todas as regiões de Governo do Estado do Rio de Janeiro. As regiões Norte, Noroeste, Serrana, Centro Sul e Baixadas Litorâneas têm ao longo da série temporal maior total pluviométrico nos meses de novembro, dezembro e janeiro. Já as regiões Metropolitana e Médio Paraíba têm maior acumulado de chuva nos meses de dezembro, janeiro e fevereiro. A exceção é a região da Costa Verde com maior quantidade de meses chuvosos em dezembro, janeiro e março.

As regiões Baixadas Litorâneas e Costa Verde apresentaram regime pluviométrico similar no tocante ao total anual precipitado. Vale ressaltar que as chuvas da região Baixadas Litorâneas foram caracterizadas a partir de estações meteorológicas localizadas na base da Serra do Mar (75\% das estações desta região), o que contribuiu para aumentar o valor médio anual da chuva calculado neste trabalho para a região. Neste contexto, ressalta-se a marcante influência da orografia complexa das Serras do Mar e da Mantiqueira na distribuição da 
chuva no estado do Rio de Janeiro. Na parte central e oeste do estado, onde ocorrem as maiores altitudes, ocorrem também os maiores totais pluviométricos do estado.

O Nordeste do ERJ, além de partes da região norte às Serras e as Norte e Noroeste, correspondem às áreas de menor pluviometria anual. Similarmente, as partes central e oeste da região Centro Sul e nordeste da região Médio Paraíba também apresentam baixos valores de chuva anual. Estas áreas estão localizadas a sotavento da Serra do Mar, e historicamente possuem chuva média anual menor do que regiões vizinhas mais a sul do estado, como a Costa Verde, Metropolitana e Baixadas Litorâneas localizadas a barlavento da Serra do Mar.

\section{REFERÊNCIAS BIBLIOGRÁFICAS}

ALMEIDA, C. T.; DELGADO, R. C.; OliveirA JÚNIOR, J. F.; GOIS, G.; CAVALCANTI, A. S. Avaliação das Estimativas de Precipitação do Produto 3B43TRMM do Estado do Amazonas. Revista Floresta e Ambiente, Seropédica, v.22, n.3, p. 279-286, 2015.

ALTAMIRANO, R. J. A. Climatologia dos eventos chuvosos e secos severos, extremos e muito extremos usando o Índice de Precipitação Normalizada (SPI) para as regiões Centro-Oeste, Sudeste e Sul do Brasil. 2010. 168f. Dissertação (Mestrado). Instituto Nacional de Pesquisas Espaciais - INPE, São José dos Campos, 2010.

ANDRÉ, R.; MARQUES, V.; PINHEIRO, F.; FERRAUDO, A. Identificação de regiões pluviometricamente homogêneas no estado do Rio de Janeiro, utilizando-se valores mensais. Revista Brasileira de Meteorologia, São Paulo, v.23, n.4, p. 501-509, 2008.

BLAIN, G. C.; KAYANO, M. T. 118 Anos de Dados Mensais do Índice Padronizado de Precipitação: Série Meteorológica de Campinas, Estado de São Paulo. Revista Brasileira de Meteorologia, São Paulo, v.26, n.1, p.137-148, 2011.

BRITO, T. T. Regiões homogêneas de precipitação e caracterização de períodos secos e úmidos no estado Do Rio De Janeiro. 2014. 89f. Dissertação (Mestrado). Programa de Pós Graduação em Engenharia de Biossistemas da Universidade Federal Fluminense (UFF), Niterói, 2014.

BRITO, T.; OLIVEIRA-JÚNIOR, J.; GOIS, G.; LYRA, G.; ZERI, M. Multivariate analysis applied to monthly rainfall over Rio de Janeiro state, Brazil. Meteorology and Atmospheric Physics (Print), Berlim, v.129, p. 469-478, 2016.

CAMBRA, M. F. E.; COELHO-NETTO, A. L.. A cidade do Rio de Janeiro e as chuvas de março/93: (Des)organização urbana e Inundações. Anuário do Instituto de Geociências (UFRJ), Rio de Janeiro, v. 20, p. 55-74, 1997.

CAMPOS, J. N. B. Secas e políticas públicas no semiárido: ideias, pensadores e períodos. Estudos Avançados, São Paulo, v.28, n.82, p.65-88, 2014.

CARVALHO, L. M. Extreme precipitation events in southeast South America and large-scale convective patterns in the South Atlantic convergence zone. Journal of Climate, Boston, v. 15, n. 17, p. 2377-94, 2002. 
CEPERJ. Estado do Rio de Janeiro Regiões de Governo. Disponível em: <http://www.ceperj.rj.gov.br/ceep/info_territorios/divis_politico_administrativo. html>. Acesso em: 6 dez. 2016.

DAVIS, E. G.; NAGHETTINI, M. Estudo de Chuvas Intensas no Estado do Rio de Janeiro. CPRM (Companhia de Pesquisa de Recursos Minerais), Rio de Janeiro, n.1, 2000. 138p.

DERECZYNSKI, C. P. OLIVEIRA, J. S.; MACHADO, C. O. Climatologia da Precipitação da Cidade do Rio de Janeiro. Revista Brasileira de Meteorologia, São Paulo, v.24, n.1, p.24-38, 2009.

DOURADO, F.; ARRAES, T. C., SILVA, M. F. O megadesastre da Região Serrana do Rio de Janeiro - as causas do evento, os mecanismos dos movimentos de massa e a distribuição espacial dos investimentos de reconstrução no pósdesastre. Anuário do Instituto de Geociências (UFRJ), Rio de Janeiro, v.35, n.2, p.43-54, 2012.

FARR, T.G., ROSEN, P.A., CARO, E., CRIPPEN, R., DUREN, R., HENSLEY, S., KOBRICK, M., PALLER, M., RODRIGUEZ, E., ROTH, L., SEAL, D., SHAFFER, S., SHIMADA, J., UMLAND, J., WERNER, M., OSKIN, M., BURBANK, D., ALSDORF, D. The Shuttle Radar Topography Mission. Review of Geophysics, Washington, v.45, n.2, p. 1-33, 2007.

GOIS, G. Catástrofes naturais no estado do Rio de Janeiro baseado em dados climáticos e produtos orbitais: uma abordagem estatística. 312f. 2017. Tese (Doutorado). Programa de Pós- Graduação em Ciências Ambientais e Florestais, Área de Concentração em Conservação da Natureza da Universidade Federal Rural do Rio de Janeiro (UFRRJ), Seropédica, 2017.

INPE; CPTEC. Produtos Climanálise. CLIMANÁLISE, 2006. <http://climanalise.cptec.inpe.br/ rclimanl/boletim/>. Acesso em: 10 abr. 2017.

KAYANO, M. T. Southeastern pacific blocking episodes and their effects on the South American weather. Meteorology and Atmospheric Physics (Print), Berlim, V.69, n.3, p.145-155, 1999.

KELLER FILHO, T.; ASSAD, E. D.; LIMA, P. R. S. R. Regiões pluviometricamente homogêneas no Brasil. Pesquisa Agropecuária Brasileira, Brasília, v.40, n.4, p.311-322, 2005.

KODAMA, Y.-M. Large-scale common features of subtropical precipitation zones (the Baiu frontal zone, the SPCZ, and the SACZ), Part I: Characteristics of subtropical frontal zones. Journal of the Meteorological Society of Japan, v. 70, p. 813-835, 1992.

KODAMA, Y. Large-Scale Common Features of Subtropical Convergence Zones (The Baiu Frontal Zone, The SPCZ and The SACZ), Part I: Conditions of the Circulations for Generating STCZs. Journal Meteorology Society of Japan, Tokyo, v.71, n.b, p.581-610, 1993a.

KODAMA, Y. Large-Scale Common Features of Subtropical Precipitation Zones (The Baiu Frontal Zone, The SPCZ and The SACZ), Part I: Characteristics of Subtropical Precipitation Zones. Journal Meteorology Society of Japan, Tokyo, v.70, n. a, p.813-836, 1993b. 
KOUSKY, V. E. Pentad outgoing longwave radiation climatology for the South American sector. Revista Brasileira de Meteorologia, n. 3, p. 217-231, 1988.

LENTERS, J. D.; COOK, K. H. Simulation and Diagnosis of the Regional Summertime Precipitation Climatology of South America. Journal of Climate, v. 8, p. 2988-3005, 1995.

LIMA, K. C.; SATYAMURTY, P.; FERNÁNDEZ, J. P. R. Large-scale atmospheric conditions associated with heavy rainfall episodes in Southeast Brazil. Theoretical and Applied Climatology, Londres, v.101, n.1, p. 121-135, 2010.

MACHADO, R. L.; CEDDIA, M. B.; CARVALHO, D. F.; CRUZ, E. S.; FRANCELINO, M. R. Variabilidade espacial da chuva máxima diária anual média e sob diferentes períodos de retorno no estado do Rio de Janeiro, Brasil. Bragantia, Campinas, v.69, supl.0, p.77-84, 2010.

MARCELINO, E. V.; NUNES, L. H.; KOBIYAMA, M. Banco de Dados de Desastres Naturais: Análise de Dados Globais e Regionais. Caminhos de Geografia, Uberlândia, v.6, n. 19, p.130-149, 2006.

MARENGO, J. A. Mudanças Climáticas Globais e seus Efeitos sobre a Biodiversidade. Caracterização do Clima Atual e Definição das Alterações Climáticas para o Território Brasileiro ao Longo do Século XXI, 2006. 201p.

MARENGO, J. A. Mudanças climáticas e eventos extremos no Brasil. Fundação Brasileira para o Desenvolvimento Sustentável, 2012. (Nota técnica).

MENDES, M. C. D. Bloqueios Atmosféricos de 1960 a 2000 sobre o Oceano Pacífico Sul: impactos Climáticos e Mecanismos Físicos Associados. Revista Brasileira de Meteorologia, São Paulo, n.20, v.2, p.175-190, 2005.

MINUZZI, R.; SEDIYAMA, G. Influência do fenômeno climático el niño no período chuvoso da região sudeste do Brasil. Geografia, Londrina, v.20, n.2, p.5-19, 2010.

MINUZZI, R.; SEDIYAMA, G.; COSTA, J. M.; VIANELLO, R. Influência da La Niña na estação chuvosa da região sudeste do Brasil. Revista Brasileira de Meteorologia, São Paulo, v.22, p. 345-353, 2007a.

MINUZZI, R.; SEDIYAMA, G.; BARBOSA, E.; MELO-JÚNIOR, J. C. Climatologia do comportamento do período chuvoso da região sudeste do Brasil. Revista Brasileira de Meteorologia, São Paulo, v.22, n.3, p.338-344, 2007b.

MORAES, N. O.; MARTON, E.; PIMENTEL, L. C. G. Simulações Numéricas da Formação de Ilha de Calor na Região Metropolitana do Rio de Janeiro. Anuário do Instituto de Geociências (UFRJ), Rio de Janeiro, v.10, n.2, p.116-138, 2005.

MORALES, C. A. R.; DA ROCHA, R. P.; BOMBARDI, R. On the development of summer thunderstorms in the city of São Paulo: Mean meteorological characteristics and pollution effect. Atmospheric Research, Londres, v.96, n.2-3, p.477-488, 2010.

MOREIRA, A; GUASSELI, L; SILVA-FILHO, L. C.; ANDRADE, A.; ARRUDA, D. Índice de Condição da Vegetação (VCI) para mapeamento de seca no Norte do Estado de Minas Gerais. In: XVII Simpósio Brasileiro de Sensoriamento Remoto - SBSR, João Pessoa, INPE, p. 1686-1692, 2015. 
NIMER, E. Climatologia da Região Sudeste do Brasil - Introdução a Climatologia Dinâmica. Revista Brasileira de Geografia, Rio de Janeiro, v.34, n.1, p.3-48, 1972.

NIMER. E. Climatologia do Brasil. 2a Edição. Rio de Janeiro: Instituto Brasileiro de Geografia e Estatística, 1989. 421p.

OLIVEIRA JÚNIOR, J.; DELGADO, R.; GOIS, G.; LANNES, A.; DIAS, F.; SOUZA, J.; SOUZA, M. Análise da precipitação e sua relação com sistemas meteorológicos em Seropédica. Floresta e Ambiente, Seropédica, v.21, n.2, p.140-149, 2014.

OLIVEIRA JÚNIOR, J. F.; TERASSI, P. M. B.; GOIS, G. Estudo da Circulação dos Ventos na Baía de Guanabara/RJ, entre 2003 e 2013. Revista Brasileira de Climatologia, Curitiba, v.21, n.1, p.59-80, 2017.

PALMER, W. C. Meteorological Drought. Research Paper No. 45, 58 p., 1965.

PEREIRA FILHO, A. J.; HAAS, R.; AMBRIZZI, T. Caracterização de eventos de enchentes na bacia do Alto Tietê por meio do radar meteorológico e da modelagem numérica de mesoescala. In: XII Congresso Brasileiro de Meteorologia, Foz do Iguaçu, p.59-80, 2002.

PIRES, V. Frequência e Intensidade de Fenómenos meteorológicos extremos associados a precipitação. 89f. Dissertação (Mestrado). Programa de Ciências e Engenharia da Terra da Universidade Nova de Lisboa, Lisboa, 2003.

REBOITA, M.; GAN, M. A.; DA ROCHA, F. P.; AMBRIZZI, T. Regimes de precipitação na América do Sul: uma revisão bibliográfica. Revista Brasileira de Meteorologia, v. 25, n. 2, p. 185-204, 2010.

SANT'ANNA NETO, J. L. Decálogo da climatologia do Sudeste brasileiro. Revista Brasileira de Climatologia, Curitiba, v.1, n.1, p.43-60, 2005.

SOARES, F.; NUNES, C.; SENNA, M. Distribuição espaço-temporal da precipitação na região hidrográfica da Baía da Ilha Grande - RJ. Revista Brasileira de Meteorologia, São Paulo, v.29, n.1, p.125-138, 2014.

SOBRAL, B. S. Caracterização da seca no estado do Rio de Janeiro baseada no índice SPI via modelo DRINC. 2017. 154f. Dissertação (Mestrado). Programa de Pós-Graduação em Engenharia de Biossistemas da Universidade Federal Fluminense (UFF), Niterói, 2017.

SMITH, R.B.; BARSTAD, I. A linear theory of orographic precipitation. Journal Atmospherics Sciences, Boston, v.61, n.12, p.1377-1391. 2004.

VERA, C.; HIGGINS, W.; AMBRIZZI, T.; AMADOR, J.; GARREAUD, R.; GOCHIS, D.; GUTZLER, D.; LETTENMAIER, D.; MARENGO, J.; MECHOSO, C. R.; NOGUESPAEGLE; . SILVA DIAS, P. L; ZHANG, C. Toward a Unified View of the American Monsoon Systems. Journal of Climate, v. 19, p. 4977-5000, 2006b.

VICENTE-SERRANO, S. M.; BEGUERÍA, S.; LÓPEZ-MORENO, J. I. A multiscalar drought index sensitive to global warming: The standardized precipitation evapotranspiration index. Journal of Climate, Boston, v.23, n.7, p.1696-1718, 2010. 
WANDERS, N.; WADA, Y. Human and climate impacts on the 21st century hydrological drought. Journal of Hydrology, Londres, v.526, n.1, p.208-220, 2015 